\title{
Structure and functional analysis of the Legionella chitinase ChiA reveals a novel mechanism of metal-dependent mucin degradation
}

Katherine H. Richardson ${ }^{1}$, Lubov S. Grigoryeva ${ }^{2}$, Paula Corsini ${ }^{1,3}$, Richard C. White ${ }^{2}$, Rosie Shaw ${ }^{1}$, Theo J. Portlock ${ }^{1,3}$, Benjamin Dorgan ${ }^{1,3}$, Arianna Fornili ${ }^{1}$, Nicholas P. Cianciotto ${ }^{2 *} \&$ James A. $^{2}$

$$
\text { Garnett }^{1,3 *}
$$

${ }^{l}$ Chemistry and Biochemistry Department, School of Biological and Chemical Sciences, Queen Mary University of London, London, UK.

${ }^{2}$ Department of Microbiology and Immunology, Northwestern University Feinberg School of Medicine, Chicago, Illinois, USA. ${ }^{3}$ Centre for Host Microbiome Interactions, Dental institute, King's College London, London, UK

*Correspondence to:

James Garnett, Centre for Host Microbiome Interactions, Dental institute, King's College London, London, UK. Tel: (+44) 0207188 8094. email: james.garnett@kcl.ac.uk

Nicholas Cianciotto, Department of Microbiology and Immunology, Northwestern University Feinberg School of Medicine, Chicago, Illinois, USA. Tel: (+1) 312503 0385. email: n-cianciotto@northwestern.edu 


\begin{abstract}
Chitinases are important enzymes that contribute to the generation of carbon and nitrogen from chitin, a long chain polymer of $\mathrm{N}$-acetylglucosamine that is abundant in insects, fungi, invertebrates and fish. Although mammals do not produce chitin, chitinases have been identified in bacteria that are key virulence factors in severe respiratory, gastrointestinal and urinary diseases. However, it is unclear how these enzymes are able to carry out this dual function. Legionella pneumophila is the causative agent of Legionnaires' disease, an often-fatal pneumonia and its chitinase ChiA is essential for the survival of L. pneumophila in the lung. Here we report the first atomic resolution insight into the pathogenic mechanism of a bacterial chitinase. We derive an experimental model of intact ChiA and show how its $\mathrm{N}$-terminal region targets ChiA to the bacterial surface after its secretion. We provide the first evidence that L. pneumophila can bind mucins on its surface but this is not dependent on chiA. This demonstrates that additional peripheral mucin binding proteins are also expressed in L. pneumophila. Finally, we show that the ChiA C-terminal chitinase domain has novel metal-dependent peptidase activity against mammalian mucins. These findings suggest that ChiA facilitates bacterial penetration of the alveolar mucosa and ChiA may be a promising target for vaccine development.
\end{abstract}

\title{
Keywords
}

peptidase, chitinase, mucin, Legionella 


\section{Introduction}

Legionella pneumophila is a Gram-negative bacterium that can withstand large variation in $\mathrm{pH}$ and temperature. When humans are exposed to L. pneumophila, it can infect macrophages and epithelia in the lungs and trigger chronic inflammation and tissue damage (1). L. pneumophila is the causative agent of Legionnaires' disease, an often-fatal pneumonia, and Pontiac fever, a milder flu-like disease, and rates of infection are increasing each year (1-4). Although infection is primarily via inhalation of contaminated water droplets from aerosolizing devices (5), there is also now evidence for person-toperson transmission $(6,7)$.

Upon invasion of eukaryotic hosts, L. pneumophila avoids fusion with canonical endosomal/lysosomal pathways by forming a membrane bound compartment, the Legionella containing vacuole (LCV) (1). L. pneumophila encodes over 300 proteins that are exported from this modified phagosome into the host cytoplasm by the Icm/Dot type IVb secretion system (1). These effectors manipulate host signalling pathways and mediate evasion of the host's degradative lysosomal pathway, enabling L. pneumophila to replicate to large numbers (8). L. pneumophila also expresses a type II secretion system (T2SS), which secretes at least 25 proteins, including almost 20 enzymes and substrates that contain a high proportion of unique amino acid sequence with no homology outside of the Legionella genus (9). The T2SS is important for both intracellular and extracellular lifestyles (9). These processes include extracellular growth at low temperatures, biofilm formation, intracellular replication in amoebae and macrophages, dampening of cytokine output from infected cells and persistence in lungs (9-15).

Among the type II substrates, ChiA is an $81 \mathrm{kDa}$ endochitinase with a novel amino acid sequence at its N-terminus and a putative glycosyl hydrolase 18 (GH18) domain at its C-terminus (15). Chitin is an insoluble carbohydrate composed of linear $\beta$-1,4-linked $\mathrm{N}$-acetylglucosamine (GlcNAc) residues and its degradation by chitinase enzymes serves as an important source of nutrients for many bacteria (16). Chitin is not synthesized by mammals and L. pneumophila chiA mutants are not impaired for growth in Vermamoeba vermiformis amoebae and macrophage-like U937 cells (15). However, they are less able to survive in the lungs of $\mathrm{A} / \mathrm{J}$ mice, suggesting that ChiA is required for optimal survival of $L$. pneumophila in the lungs (15), although how it is able to promote infection is unknown.

In this study, we report a structural model for full-length ChiA based on X-ray crystallographic, template based modelling and small angle X-ray scattering (SAXS) data. ChiA is composed of four domains (N1, N2, N3 and CTD, from N- to C-terminus) which have structural homology to those associated with other chitinase enzymes. Using chitin binding and chitinase activity assays, we show that ChiA-N1 is a chitin binding module and we confirm that ChiA-CTD is a glycosyl hydrolase domain. Using binding assays, we show that both the ChiA-N3 domain and eukaryotic mucins can associate with the L. pneumophila surface. Lastly, our structural and biochemical studies demonstrate 
that ChiA-CTD has novel mucinase activity, independent of its chitinase active site. Our work provides novel molecular insight into the virulence mechanism of a bacterial chitinase and suggests that ChiA has a role in liberating nutrients and facilitating L. pneumophila penetration of the alveolar mucosa.

\section{Results}

ChiA is a multi-domain protein. Full-length ChiA from L. pneumophila 130b (ChiA-FL; numbered 1-762 for the mature protein; NCBI accession WP_072401826.1) with an N-terminal His 6 -tag was produced in Escherichia coli K12 and purified by nickel-affinity and size exclusion chromatography. Despite extensive screening ChiA-FL resisted crystallization and we therefore used bioinformatics analysis to produce a series of subdomain constructs for further characterization (Fig. 1A). While previous examination of the C-terminal domain of ChiA (ChiA-CTD: residues 419-762) had revealed high primary sequence homology to other GH18 chitinase domains (15), the N-terminal region (ChiANT; residues 1-417) contains unique primary sequence with no significant homology to any other known protein. Nonetheless, through secondary structure prediction (17) and template based modelling using the Phyre2 (18) and Robetta (19) servers, we identified three putative N-terminal subdomains based on predicted structural similarity with carbohydrate-binding modules (CBMs; ChiA-N1: residues 1-140), fibronectin type-III-like domains (Fn3; ChiA-N2: residues 138-299) and a chitinase A Nterminal domain (ChiN; ChiA-N3: residues 285-417) (Fig. 1A, Table S1).

To examine the function of the ChiA N-terminal domains we began by examining their endochitinase activity (15). Each construct was expressed with an N-terminal His $6_{6}$-tag in E. coli K12 and purified by nickel-affinity and size exclusion chromatography. All reagents were well folded as determined by $1 \mathrm{D}$ ${ }^{1} \mathrm{H}$ nuclear magnetic resonance (NMR) spectroscopy (Fig. S1). As expected ChiA-FL and ChiA-CTD were both active against $p$-nitrophenyl $\beta$-D- $N, N^{\prime}, N^{\prime \prime}$ triacetylchitotriose ( $p$ NP-[GlcNAc $]_{3}$ ) but no activity was detected for ChiA-NT or an E543M ChiA-CTD active site mutant (ChiA-CTD ${ }^{\text {E543M }}$ ) (Fig. 1B, S2). We then assayed binding of ChiA sub-domains to immobilized chitin and observed that in addition to ChiA-CTD, the N1-domain also recognizes chitin polymers, which supports its role as a carbohydrate binding module (Fig. 1C, S3).

Atomic structure of ChiA-CTD. We next initiated crystallographic studies of the ChiA subdomains. We readily obtained crystals for ChiA-CTD and its structure was determined using iodide single isomorphous replacement with anomalous scattering (I-SIRAS) phasing. Electron-density maps were refined to $1.7 \AA$ (Table S2) and the final model contains two identical chains, with all molecules built except for the N-terminal His6-tags and adjacent ChiA-CTD residues Val419 to Gly424. Each chain forms an anticipated GH18 $\alpha / \beta$-fold and is composed of $11 \beta$-strands and $13 \alpha$-helices (Fig. 2A). High 
concentrations of 2-methyl-2,4-pentanediol (MPD) were used as a precipitant during crystallization and we observed four MPD molecules in the final model; one bound to the catalytic Asp541 and Glu543 residues (MPD-1) and one within a hydrophobic pocket formed by the $\alpha 5$ helix and $\alpha 5-\alpha 5^{\prime} / \beta 5$ $\beta 6^{\prime}$ loops (MPD-2) (Fig. S4).

The overall structure of ChiA-CTD is highly similar to other GH18 chitinase domains, and the Dali server (20) identified Bacillus cereus ChiNCTU2 enzyme inactive E145G/Y227F mutant in complex with chitotetrose (Protein Data Bank (PDB) ID code 3n18) (21); Bacillus anthracis Chi36 (PDB ID code 5kz6); Chromobacterium violaceum ChiA (PDB ID code 4tx8); and Streptomyces coelicolor ChiA (PDB ID code 3ebv) as having the highest homologies ( $\mathrm{Z}$ score: 36.3, 35.9, 34.4, 34.1 respectively; rmsd: $2.2 \AA, 2.3 \AA, 2.2 \AA, 1.8 \AA$, respectively). The chitinase active sites of ChiNCTU2 and ChiA-CTD have high primary sequence identity and tertiary structure homology (Fig. 2B, S5) and modelling of chitotetrose binding indicates that chitin lines a negatively charged valley on the surface of ChiA-CTD. Chitotetrose overlays with MPD-1 in the active site (Fig. 2C, D, S4) and the MPD-2 site is positioned adjacent to the reducing end of the modelled chitotetrose. However, L. pneumophila ChiA-CTD also possesses unique features that are not observed in homologous structures. These include an additional $\alpha$-helix ( $\alpha 3$ ), an extended $\beta 3-\alpha 3$ loop, an extended $\alpha 6-\alpha 6^{\prime}$ loop and an extended $\beta 7-\alpha 7$ loop (Fig. 2A, S5, S6).

ChiA is an elongated and dynamic structure in solution. We used small angle X-ray scattering (SAXS) to model the global structure of full-length ChiA in solution. Four different concentrations at $4,2,1$, and $0.5 \mathrm{mg} / \mathrm{ml}$ were measured but signs of aggregation were apparent at concentrations above $1 \mathrm{mg} / \mathrm{ml}$ (data not shown). To achieve the highest signal/noise ratio, all further analysis was carried out with the data from the $1 \mathrm{mg} / \mathrm{ml}$ sample (Fig. S7, Table S3). Guinier analysis suggested a radius of gyration $\left(R_{\mathrm{g}}\right)$, the root mean square distance to the particles centre of mass, of $5.43 \mathrm{~nm}$ and analysis of the distance distribution function $(\mathrm{P}(\mathrm{r}))$ suggested a maximum particle dimension $\left(D_{\max }\right)$ of $17.77 \mathrm{~nm}$ and $R_{\mathrm{g}}$ of $5.45 \mathrm{~nm}$ (Fig. S7). Using BSA as a standard, we calculated a particle molecular mass of 89.2 $\mathrm{kDa}$, which is within the method error range for a monomeric $82.6 \mathrm{kDa}$ ChiA.

Kratky, Kratky-Debye and Porod-Debye plot analyses of the SAXS data indicated that ChiA is a highly dynamic particle in solution (Fig. S7) (22). This is likely due to flexibility within the ChiA inter-domain linkers and we therefore used the ensemble optimization method (EOM) to determine molecular model ensembles of ChiA that best fit the SAXS data (23). As we were not able to obtain crystals for ChiA Ndomains, an initial model of ChiA was created using a Phyre2 derived N1-domain (residues 22-147), a Robetta derived N2-domain (encompassing two further subdomains: residues 152-245 and 248-305), a Phyre2 derived ChiA N3-domain (residues 315-414) and the crystal structure of ChiA-CTD (residues 439-777), separated by flexible linkers (Fig. 3A; Table S1) (18, 19, 23). Ensemble optimization 
analysis of the scattering data again supported ChiA being highly flexible in solution ( $\mathrm{R}_{\text {flex }}$ 91.4) (24), with conformation ensembles clustered within three populations (Fig. 3B, C; Table S4). The majority of the simulated conformations exhibited partially extended or fully extended structures at $R g$ 44-56 $\AA$ or $R_{g}$ 60-71 $\AA$, respectively, whereas minor conformations of closed structures were also populated at $R_{g}$ 33-43 Å. Inter-domain flexibility is a key feature of processive enzymes (25) and these data suggest that processivity is also important for ChiA function.

ChiA is targeted to the L. pneumophila surface. Although we have repeatedly detected secreted ChiA in bacterial culture supernatants $(15,26)$, it has been well documented in other bacteria that some type II substrates associate with the bacterial surface upon their secretion $(27,28)$. To determine whether ChiA is also targeted to the bacterial surface, L. pneumophila $130 \mathrm{~b}$ was examined by whole-cell ELISA using anti-ChiA, anti-Mip and anti-ProA antibodies (Fig. 4A). Both ChiA and Mip, a known surface exposed protein (29), were positive by ELISA, whilst the metalloprotease ProA, another T2SS substrate $(9,30)$, was negative. To establish which region of ChiA is responsible for this localization, $L$. pneumophila NU318 (chiA) mutant was incubated with recombinant ChiA fragments and the wholecell ELISA was repeated using ChiA antisera (Fig. 4B). ChiA-NT and the N3-domain exhibited significant binding to the bacterial surface while no binding was observed for ChiA-CTD, ChiA-N1 or ChiA-N2.

ChiA is a mucin binding protein. Some bacterial chitinases and chitin binding proteins are able to promote infection through adhesion to and/or degradation of host glycoconjugates (31) and we hypothesized that ChiA may interact with exogenous mucins in the lungs and elsewhere. We therefore examined the binding capacity of recombinant ChiA-FL and ChiA domains to immobilized commercially available mucin extracts by ELISA using anti-His antibodies (Fig. 4C). All ChiA samples displayed significant adhesion to mucins isolated from porcine stomachs (type II and III) but this was not observed with a mucin extract from bovine submaxillary glands (type I-S). This confirms that ChiA has additional specificity for non-chitinous ligands and implies that ChiA could mediate the attachment of host glycoproteins to the Legionella surface. To assess this, we incubated L. pneumophila 130b wildtype and NU318 (chiA) mutant strains with type I-S, II and III mucin extracts followed by wheat germ agglutinin and measured their binding to the bacterial surface by flow cytometry. Whether examined at $25^{\circ} \mathrm{C}$ or $37^{\circ} \mathrm{C}$, type II and III extracts showed strong association to both L. pneumophila strains (Fig. 4D) but submaxillary gland mucins did not (data not shown). However, there was no significant difference in binding of the type II and III mucins between wild-type and chiA mutant strains, which indicates that other factors apart from ChiA are present on the Legionella surface that can also recognize mucins and in the case of the mutant, compensate for the loss of ChiA. 
ChiA-CTD is a metal-dependent mucinase. We next examined whether secreted ChiA is able to degrade mucins. Porcine stomach type II mucin extract was incubated with supernatants from $L$. pneumophila 130b wild-type and NU318 (chiA) mutant strains or a cocktail of enzymes (pepsin, pronase, $\beta$-N-acyltylglucosamidase, fucosidase) with known activity against mucins, and then analysed by immunoblotting using wheat germ agglutinin (Fig. 5A, left panel). While the majority of the mucin extract ran at $>500 \mathrm{kDa}$, after incubation with the mucinase cocktail there was a reduction in high molecular weight species and the appearance of a new band at $\sim 200 \mathrm{kDa}$. When the extract was incubated with $L$. pneumophila $130 \mathrm{~b}$ wild-type supernatant there was again a reduction of high molecular weight material but also addition of a fragment at $\sim 100 \mathrm{kDa}$, while the chiA mutant supernatant produced a profile that was more similar to the control. When the experiment was performed using a greater amount of mucin, the difference between the wild type and mutant was even more evident, revealing that the presence of the $100 \mathrm{kDa}$ degradation product was dependent upon ChiA (Fig 5A, right panel).

We then tested the ability of recombinant ChiA to degrade type II mucin extracts in vitro by immunoblotting and compared its profile to that of recombinant SslE mucinase, an E. coli M60 family aminopeptidase (32). Incubation of type II mucin with ChiA-FL and SslE resulted in a significant reduction of detectable carbohydrate, showing that both enzymes process mucins into lower molecular weight fragments and confirmed that L. pneumophila degradation of mucins is a direct result of ChiA activity. (Fig. 5B). SslE uses a HExxH motif to coordinates $\mathrm{Zn}^{2+}$ in its active site (33) and in the presence of the metal chelating agent ethylenediaminetetraacetic acid (EDTA) we could not detect activity for SslE. Likewise, in the presence of EDTA ChiA-FL could not process mucins which demonstrates that the mucinase activity of ChiA is also metal-dependent.

ChiA-CTD is a novel peptidase. Mucins contain a large number of serine/threonine rich repeat sequences which are highly O-glycosylated (34). Analysis of the type II mucin extract by $1 \mathrm{D}{ }^{1} \mathrm{H}-\mathrm{NMR}$ revealed sharp peaks that originate from partially degraded low molecular weight mucin fragments and we used this to further probe changes in the mucin structure on addition of ChiA. Incubation with ChiAFL, ChiA-CTD and SslE but not ChiA-NT resulted in a loss of signal in the type II mucin extract at $\sim 1.2 \mathrm{ppm}$ and between $\sim 2.5$ to $\sim 2.8 \mathrm{ppm}$ and $\sim 3.8$ to $4.2 \mathrm{ppm}$, whilst in the presence EDTA no significant changes were observed (Fig. 5C, S8). The degradation profile of the type II mucin extract incubated with ChiA-CTD and SslE were identical and changes in the ${ }^{1} \mathrm{H}-\mathrm{NMR}$ spectra are localized to the expected chemical shift ranges for non-anomeric carbohydrate ring protons and the amino acids side chain protons of aspartate, asparagine and threonine. This clearly shows that the $\mathrm{C}$-terminal domain of ChiA has dual enzymatic activity and supports ChiA and SslE having similar peptidase mechanisms for the degradation of mucins. 
To evaluate this further we performed Molecular Dynamics (MD) simulations and examined the ability of ChiA-CTD to bind $\mathrm{Zn}^{2+}$ in silico. The protein was 'soaked' in a water solution at high $\mathrm{Zn}^{2+}$ concentration and the system was then left to evolve over time to identify the regions on the protein surface where $\mathrm{Zn}^{2+}$ ions tend to bind. Multiple short simulations were run starting from different random placements of $\mathrm{Zn}^{2+}$ ions, for an aggregated simulation time of $1.7 \mu \mathrm{s}$. Analysis of the $\mathrm{Zn}^{2+}$ spatial distribution function (sdf) calculated on the concatenated trajectories highlighted multiple high $\mathrm{Zn}^{2+}$ density sites in the region around the chitinase active site, providing information on the different ways in which $\mathrm{Zn}^{2+}$ could bind to the protein in this region. The highest density was found at the chitinase active site (region 1), where $\mathrm{Zn}^{2+}$ is coordinated by Asp541, Glu543 and Gln617, with two other sites in close proximity (regions 2,3) coordinated by Glu543 and Q583 (Fig. 6). Binding of zinc in the active site of Bacillus cereus ChiNCTU2 has been shown to inhibit chitinase activity (21) and indicates that metal binding could modulate the different enzyme activities in ChiA.

A unique cluster of $\mathrm{Zn}^{2+}$ sites was also located away from the chitinase active site, near the MPD-2 ligand site in the ChiA-CTD crystal structure, involving residues Asp504 (region 4), His544 (region 5), Glu543 and Gln595 (region 6), Asn547 (region 7) and His506 (region 8) (Fig. 6). To assess whether this second cluster could coordinate a mucinase active site metal we created D504A, H506A, H544A, N547A and Q595A mutants in ChiA-CTD (Fig. S2). All mutants retained their ability to bind chitin in pull-down experiments (Fig. S9) and bind immobilized type II and III mucin extracts in ELISA assays (Fig. S10). We then incubated these proteins and ChiA-CTD ${ }^{\mathrm{E} 543 \mathrm{M}}$ with type II mucin extract and inspected their degradation profiles by ${ }^{1} \mathrm{H}$ NMR. Mucin incubated with ChiA-CTD ${ }^{\mathrm{D} 504 \mathrm{~A}}$, ChiA$\mathrm{CTD}^{\mathrm{H} 544 \mathrm{~A}}$, ChiA-CTD ${ }^{\mathrm{N} 547 \mathrm{~A}}$ and ChiA-CTD ${ }^{\mathrm{Q} 595 \mathrm{~A}}$ all produced identical NMR spectra that showed no degradation, while mucins incubated with ChiA-CTD ${ }^{\mathrm{H} 506 \mathrm{~A}}$ or ChiA-CTD ${ }^{\mathrm{E} 543 \mathrm{M}}$ showed loss of signals at $\sim 1.2 \mathrm{ppm}$ and between $\sim 2.5$ to $\sim 2.8 \mathrm{ppm}$ and $\sim 3.8$ to $4.2 \mathrm{ppm}$ equivalent to that of native ChiA-CTD (Fig. 7A). This confirms that Asp504, His544, Asn547 and Gln595 form a unique peptidase active site in ChiA which is independent from the adjacent glycosyl hydrolase active site (Fig. 7B).

\section{Discussion}

Chitin is highly abundant in the environment and can function as a source of carbon and nitrogen (35) but several chitinases have been identified as key virulence factors in bacterial disease (31). These include Enterococcus faecalis efChiA, E. coli ChiA, Vibrio cholerae ChiA2, Francisella tularensis ChiA, Listeria monocytogenes $\mathrm{ChiA}$ and $\mathrm{ChiB}$, Pseudomonas aeruginosa ChiC, Salmonela Typhimurium ChiA and L. pneumophila ChiA. Although it is unclear how these enzymes perform these dual functions, there is strong evidence that they interact with host glycoconjugates and through their localization and/or enzymatic activity are able to modulate host defence mechanisms (31). We have 
determined that L. pneumophila ChiA has activity against stomach derived mucins and produces an identical degradation profile to the M60-family E. coli zinc-aminopeptidase SslE $(36,37)$. Recent structural analysis of Bacteroides thetaiotaomicron BT4244, Pseudomonas aeruginosa IMPa and Clostridium perfringens $\mathrm{ZmpB}$ M60 proteins has revealed unique structural adaptations that allow them to accommodate different glycan sequences while all cleaving the peptide bond immediately preceding the glycosylated residue (33). Similarly, enterohemorrhagic E. coli StcE is an M66-family zinc metalloprotease that recognizes distinct peptide and glycan motifs in mucins and then cleaves the peptide backbone using an extended HExxHxxGxxH motif $(38,39)$. We have shown that $L$. pneumophila ChiA functions in a similar fashion to SslE but as it does not contain a HEXXH motif, ChiA represents a new class of peptidase that can degrade mammalian mucins via a novel mechanism.

We have identified four residues in ChiA that are essential for peptidase activity (Asp504, His544, Asn547 and Gln595) and likely function by coordinating a $\mathrm{Zn}^{2+}$ or other catalytic metal (33). While Asp504 is located in an augmented $\alpha 3$ helix, His544, Asn547 and Gln595 are positioned within conserved GH18 secondary structure (Fig. S5). However, sequence alignment of L. pneumophila ChiA with other virulent bacterial chitinases, including the mucin degrading $V$. cholerae ChiA2 (40), does not show conservation of these residues and modelling of their tertiary structures using the Phyre2 server (18) also highlights significant differences within their chitin binding surfaces. This implies that other virulent bacterial chitinases either promote pathogenesis using an alternative mechanism or that the specific location of the peptidase active site is unique to each enzyme and shapes their glycan specificity and function.

Mucins are heavily glycosylated cell surface exposed transmembrane proteins or secreted gel-forming proteins of the mucosal barrier that act as a first line of defence against bacterial infection and vary significantly in their structures and glycosylation profiles (41). Mucins derived from the lung are not commercially available but we have shown that ChiA has specificity for and can degrade mucins purified from the porcine stomach. The normal stomach mucosa is characterised by expression of MUC1, MUC5AC, and MUC6 mucins (42), however, MUC1 and MUC5AC are also major mucins expressed in the human airway and lung (43). MUC5AC is composed of T-antigen (Gal $\beta 1$ 3GalNAc $\alpha$ Ser/Thr), core 2 (GlcNAc $\beta 1-6(G a 1 \beta 1-3)$ GalNAc $\alpha$ Ser/Thr) and sialyl T-antigen (NeuAc $\alpha 2-$ 6(Galß1-3)GalNAcaSer/Thr) core glycan structures (44) and within the ChiA C-terminal domain the MPD-2 and chitin binding sites have obvious potential to capture these GlcNAc-like linear and branched chains (Fig. 7B). Our data suggests that ChiA can process major mucins expressed in the lung and liberate nutrients and/or facilitate bacterial penetration of the alveolar mucosa.

Secreted ChiA has been detected in bacterial culture supernatants and during L. pneumophila infection of cultured amoebae and human macrophages $(15,26)$. We previously observed that in the early stages 
of macrophage infection ChiA and another type II substrate ProA are exported to the host cytoplasm and localize to the surface of the LCV (26). The ability of ChiA to bind non-chitin substrates implies that during intracellular infection ChiA interacts with other specific host cytoplasmic glycoproteins and may modulate host pathways either through their requisitioning to the LCV or through their hydrolysis. In this study we have now shown that ChiA can also bind the L. pneumophila surface, through its N3 domain, although ProA does not. In other bacteria, type II substrates can associate with their outer membrane via acetylation of their N-terminus, interactions with other outer membrane proteins or through recognition of lipopolysaccharides $(27,28)$. While the mechanism by which ChiA is targeted to the Legionella outer membrane is still unclear, this may be shared during localization of ChiA to the LCV, yet interactions that tether ProA to the LCV are clearly not also present on the L. pneumophila surface.

Our examination of recombinant ChiA subdomains has revealed that the $\mathrm{N}$-terminal domains and $\mathrm{C}$ terminal chitinase/peptidase domain can all bind porcine stomach mucins and implies that host mucins can be sequestered and processed on the bacterial surface. However, we did not observe significant differences between mucin binding to L. pneumophila $130 \mathrm{~b}$ wild-type or chiA mutant strains. This demonstrates that additional uncharacterized mucin binding proteins are also present on the bacterial surface and indicates that manipulation of the host musosa is an important pathogenic mechanism of $L$. pneumophila. The multifaceted nature of ChiA makes it a highly versatile virulence factor of $L$. pneumophila and likewise a target for controlling L. pneumophila infection. As a surface associated protein ChiA is a promising vaccine target and our structural characterization may provide a platform to initiate vaccine development.

\section{Acknowledgements}

KHR, RS and JAG were supported by the MRC (MR/M009920/1). PC was supported by the Academy of Medical Sciences/Wellcome Trust (SBF002/1150). TJP was supported by an EPSRC studentship and BD was supported by a BBSRC studentship. Work in the Cianciotto lab was supported by NIH grant R01AI 043987. LSG and RCW were also partly supported by NIH training grants T32 GM08061 and T32 AI0007476, respectively. We thank the beamline scientists at I02, I04 and B21 of the Diamond Light Source. This work was supported by the Francis Crick Institute through provision of access to the MRC Biomedical NMR Centre. The Francis Crick Institute receives its core funding from Cancer Research UK (FC001029), the UK Medical Research Council (FC001029), and the Wellcome Trust (FC001029). MD simulations were performed using time on ARCHER granted via HECBioSim, supported by EPSRC (EP/L000253/1). 


\section{Author Contributions}

Conceived and designed the experiments: KHR, LSG, PC, RW, AF, NPC, JAG. Performed the experiments: KHR, LSG, PC, RCW, RS, TP, BD, AF, JAG. Analyzed the data: KHR, LSG, PC, RCW, AF, NPC, JAG. Contributed reagents/materials/analysis tools: AF, NPC, JAG. Wrote the paper: AF, NPC, JAG.

\section{References}

1. Newton HJ, Ang DK, van Driel IR, \& Hartland EL (2010) Molecular pathogenesis of infections caused by Legionella pneumophila. Clin Microbiol Rev 23(2):274-298.

2. Parr A, Whitney EA, \& Berkelman RL (2015) Legionellosis on the Rise: A Review of Guidelines for Prevention in the United States. J Public Health Manag Pract 21(5):E17-26.

3. Control CfD \& Prevention (2011) Legionellosis---United States, 2000-2009. MMWR. Morbidity and mortality weekly report 60(32):1083.

4. Edelstein PH \& Christian L (2015) Legionella. Manual of Clinical Microbiology, Eleventh Edition, (American Society of Microbiology), pp 887-904.

5. van Heijnsbergen E, et al. (2015) Confirmed and Potential Sources of Legionella Reviewed. Environ Sci Technol 49(8):4797-4815.

6. Borges V, et al. (2016) Legionella pneumophila strain associated with the first evidence of person-to-person transmission of Legionnaires' disease: a unique mosaic genetic backbone. Sci Rep 6:26261.

7. Correia AM, et al. (2016) Probable Person-to-Person Transmission of Legionnaires' Disease. N Engl J Med 374(5):497-498.

8. Hubber A \& Roy CR (2010) Modulation of host cell function by Legionella pneumophila type IV effectors. Annu Rev Cell Dev Biol 26:261-283.

9. White RC \& Cianciotto NP (2019) Assessing the impact, genomics and evolution of type II secretion across a large, medically important genus: the Legionella type II secretion paradigm. Microb Genom.

10. Mallama CA, McCoy-Simandle K, \& Cianciotto NP (2017) The Type II Secretion System of Legionella pneumophila Dampens the MyD88 and Toll-Like Receptor 2 Signaling Pathway in Infected Human Macrophages. Infect Immun 85(4).

11. Rossier O, Starkenburg SR, \& Cianciotto NP (2004) Legionella pneumophila type II protein secretion promotes virulence in the $\mathrm{A} / \mathrm{J}$ mouse model of Legionnaires' disease pneumonia. Infect Immun 72(1):310-321.

12. McCoy-Simandle K, et al. (2011) Legionella pneumophila type II secretion dampens the cytokine response of infected macrophages and epithelia. Infect Immun 79(5):1984-1997. 
13. White RC \& Cianciotto NP (2016) Type II Secretion Is Necessary for Optimal Association of the Legionella-Containing Vacuole with Macrophage Rab1B but Enhances Intracellular Replication Mainly by Rab1B-Independent Mechanisms. Infect Immun 84(12):3313-3327.

14. White RC, et al. (2018) Type II Secretion-Dependent Aminopeptidase LapA and Acyltransferase PlaC Are Redundant for Nutrient Acquisition during Legionella pneumophila Intracellular Infection of Amoebas. MBio 9(2).

15. DebRoy S, Dao J, Soderberg M, Rossier O, \& Cianciotto NP (2006) Legionella pneumophila type II secretome reveals unique exoproteins and a chitinase that promotes bacterial persistence in the lung. Proc Natl Acad Sci U S A 103(50):19146-19151.

16. Keyhani NO \& Roseman S (1999) Physiological aspects of chitin catabolism in marine bacteria. Biochim Biophys Acta 1473(1):108-122.

17. McGuffin LJ, Bryson K, \& Jones DT (2000) The PSIPRED protein structure prediction server. Bioinformatics 16(4):404-405.

18. Kelley LA, Mezulis S, Yates CM, Wass MN, \& Sternberg MJ (2015) The Phyre2 web portal for protein modeling, prediction and analysis. Nat Protoc 10(6):845-858.

19. Kim DE, Chivian D, \& Baker D (2004) Protein structure prediction and analysis using the Robetta server. Nucleic Acids Res 32(Web Server issue):W526-531.

20. Holm L \& Rosenstrom P (2010) Dali server: conservation mapping in 3D. Nucleic Acids Res 38(Web Server issue):W545-549.

21. Hsieh YC, et al. (2010) Crystal structures of Bacillus cereus NCTU2 chitinase complexes with chitooligomers reveal novel substrate binding for catalysis: a chitinase without chitin binding and insertion domains. J Biol Chem 285(41):31603-31615.

22. Rambo RP \& Tainer JA (2011) Characterizing flexible and intrinsically unstructured biological macromolecules by SAS using the Porod-Debye law. Biopolymers 95(8):559-571.

23. Bernado P, Mylonas E, Petoukhov MV, Blackledge M, \& Svergun DI (2007) Structural characterization of flexible proteins using small-angle X-ray scattering. $J$ Am Chem Soc 129(17):5656-5664.

24. Tria G, Mertens HD, Kachala M, \& Svergun DI (2015) Advanced ensemble modelling of flexible macromolecules using X-ray solution scattering. IUCrJ 2(Pt 2):207-217.

25. Szabo B, et al. (2019) Intrinsically Disordered Linkers Impart Processivity on Enzymes by Spatial Confinement of Binding Domains. Int J Mol Sci 20(9).

26. Truchan HK, Christman HD, White RC, Rutledge NS, \& Cianciotto NP (2017) Type II Secretion Substrates of Legionella pneumophila Translocate Out of the Pathogen-Occupied Vacuole via a Semipermeable Membrane. MBio 8(3).

27. Rondelet A \& Condemine G (2013) Type II secretion: the substrates that won't go away. Res Microbiol 164(6):556-561.

28. Cianciotto NP \& White RC (2017) Expanding Role of Type II Secretion in Bacterial Pathogenesis and Beyond. Infect Immun 85(5).

29. Cianciotto NP \& Fields BS (1992) Legionella pneumophila mip gene potentiates intracellular infection of protozoa and human macrophages. Proc Natl Acad Sci US A 89(11):5188-5191. 
30. Dreyfus LA \& Iglewski BH (1986) Purification and characterization of an extracellular protease of Legionella pneumophila. Infect Immun 51(3):736-743.

31. Frederiksen RF, et al. (2013) Bacterial chitinases and chitin-binding proteins as virulence factors. Microbiology 159(Pt 5):833-847.

32. Luo Q, et al. (2014) Enterotoxigenic Escherichia coli secretes a highly conserved mucindegrading metalloprotease to effectively engage intestinal epithelial cells. Infect Immun 82(2):509-521.

33. Noach I, et al. (2017) Recognition of protein-linked glycans as a determinant of peptidase activity. Proc Natl Acad Sci U S A 114(5):E679-E688.

34. Baldus SE, Engelmann K, \& Hanisch FG (2004) MUC1 and the MUCs: a family of human mucins with impact in cancer biology. Crit Rev Clin Lab Sci 41(2):189-231.

35. Beier S \& Bertilsson S (2013) Bacterial chitin degradation-mechanisms and ecophysiological strategies. Front Microbiol 4:149.

36. Valeri M, et al. (2015) Pathogenic E. coli exploits SslE mucinase activity to translocate through the mucosal barrier and get access to host cells. PLoS One 10(3):e0117486.

37. Hooper NM (1994) Families of zinc metalloproteases. FEBS Lett 354(1):1-6.

38. Yu AC, Worrall LJ, \& Strynadka NC (2012) Structural insight into the bacterial mucinase StcE essential to adhesion and immune evasion during enterohemorrhagic E. coli infection. Structure 20(4):707-717.

39. Malaker SA, et al. (2019) The mucin-selective protease StcE enables molecular and functional analysis of human cancer-associated mucins. Proc Natl Acad Sci US A 116(15):7278-7287.

40. Mondal M, Nag D, Koley H, Saha DR, \& Chatterjee NS (2014) The Vibrio cholerae extracellular chitinase ChiA2 is important for survival and pathogenesis in the host intestine. PLoS One 9(9):e103119.

41. Johansson ME \& Hansson GC (2016) Immunological aspects of intestinal mucus and mucins. Nat Rev Immunol 16(10):639-649.

42. Ho SB, et al. (1995) Mucin gene expression in normal, preneoplastic, and neoplastic human gastric epithelium. Cancer Res 55(12):2681-2690.

43. Lai H \& Rogers DF (2010) New pharmacotherapy for airway mucus hypersecretion in asthma and COPD: targeting intracellular signaling pathways. J Aerosol Med Pulm Drug Deliv 23(4):219-231.

44. Evert C, et al. (2019) Generation of (13)C-Labeled MUC5AC Mucin Oligosaccharides for Stable Isotope Probing of Host-Associated Microbial Communities. ACS Infect Dis 5(3):385393. 


\section{Figures}

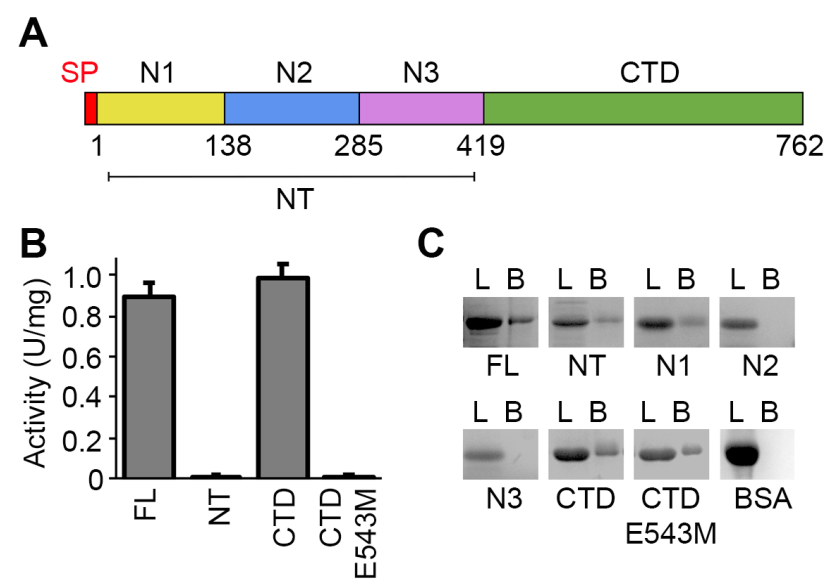

Figure 1: Chitin binding and endochitinase functions of ChiA. (A) Schematic representation of ChiA with domain boundaries annotated. (B) ChiA-FL, subdomains (NT, N1, N2, N3, CTD) and ChiA$\mathrm{CTD}^{\mathrm{E} 543 \mathrm{M}}$ were assayed for chitinase activity against $p$-NP-[GlcNAc $]_{3}$. Data represent the mean and standard deviation for triplicate experiments. (C) Chitin pull-down experiment to assess direct interactions between immobilized chitin and ChiA. ChiA-FL and subdomains (NT, N1, N2, N3, CTD, $\mathrm{CTD}^{\mathrm{E} 543 \mathrm{M}}$ ) were incubated with chitin beads and analysed by SDS-PAGE. BSA was used as a control. L: loaded sample; B: eluted beads. Data is representative of three independent repeat experiments. 

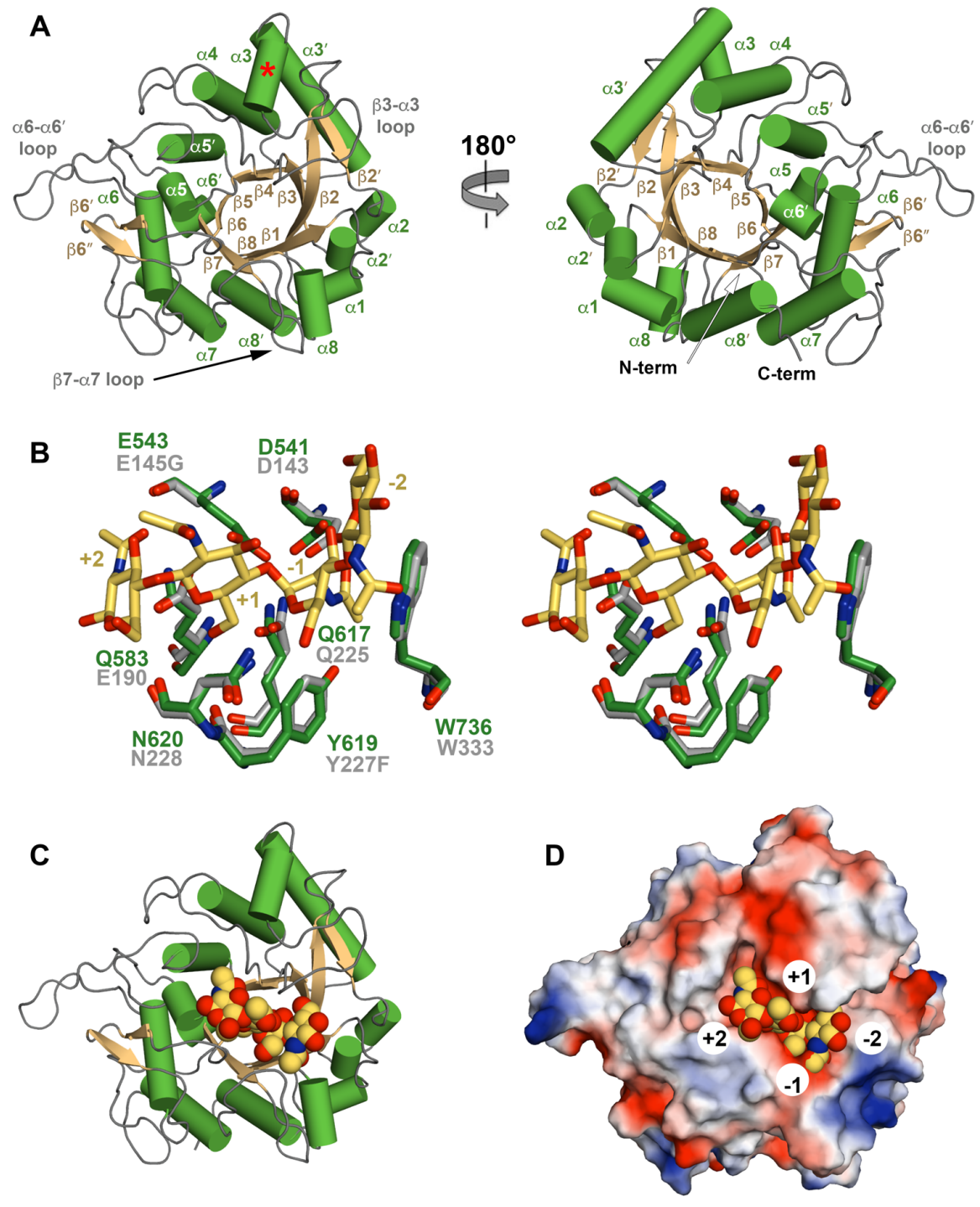

Figure 2: Crystal structure of ChiA-CTD. (A) Cartoon representation of ChiA-CTD with secondary structure and extended loops annotated. Additional ChiA-CTD $\alpha 3$-helix is highlighted with a red asterisk. (B) Stick representation of the ChiA-CTD active site (green) superimposed with ChiNCTU2 E145G/Y227F mutant (grey) in complex with chitotetrose (yellow) (PDB ID code 3n18) (21). Mutated residues in ChiNCTU2 are indicated and carbohydrate positions relative to the hydrolysed glycosidic bond are numbered. (C) Model of ChiA-CTD shown as cartoon and (D) electrostatic surface potential, bound to chitotetrose drawn as spheres. 
A

C

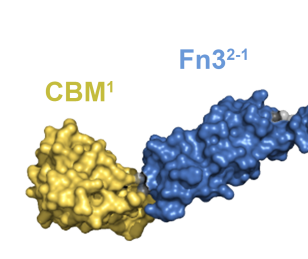

$\mathrm{Fn}^{2-2}$

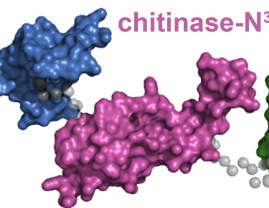

N2

N3 chitinase $^{4}$
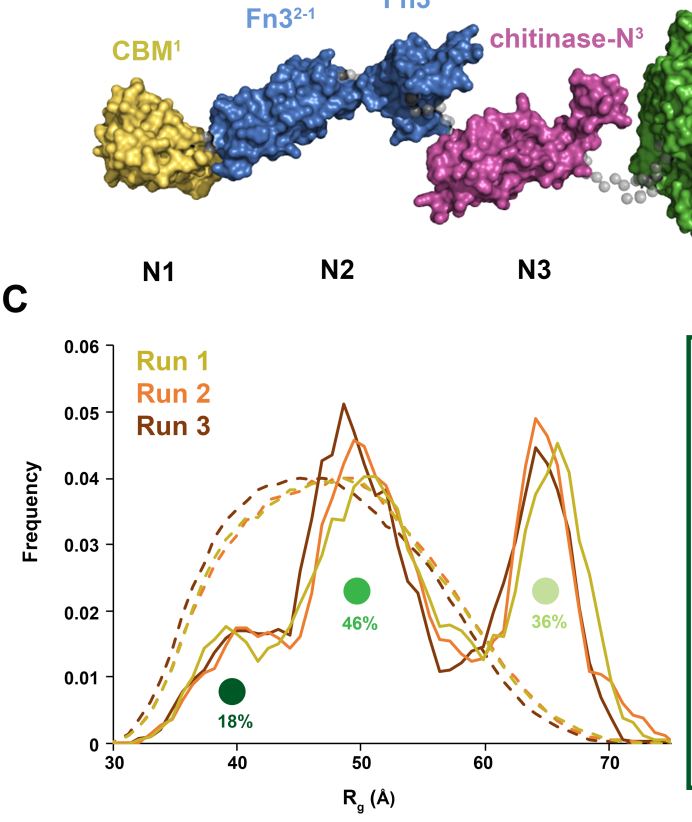

CTD

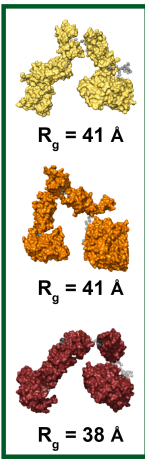

B

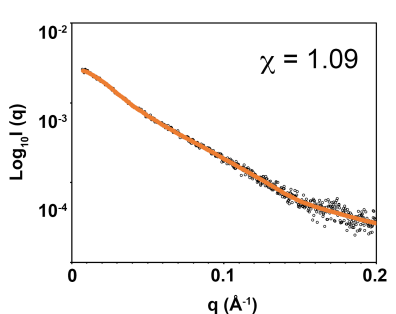

$q\left(\AA^{-1}\right)$

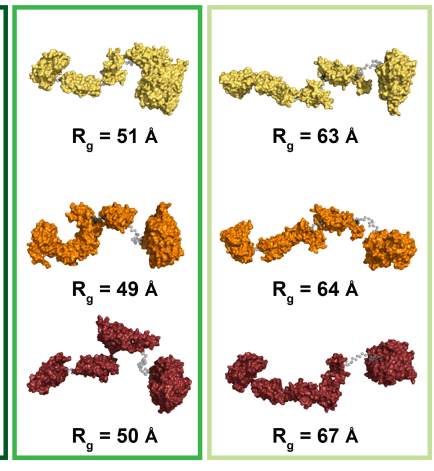

Figure 3: Model of ChiA-FL in solution. (A) Initial model of ChiA generated by EOM 2.0 (24). Linkers are shown as grey spheres. (B) EOM fit (orange line) to the ChiA SAXS data (black open circles) with $\chi^{2}$ of 1.09. (C) Three independent ensemble optimization method runs (yellow, orange and burgundy) yielded similar distributions of three populations. Sample ChiA models corresponding to the centre of each population for all three runs are shown. 

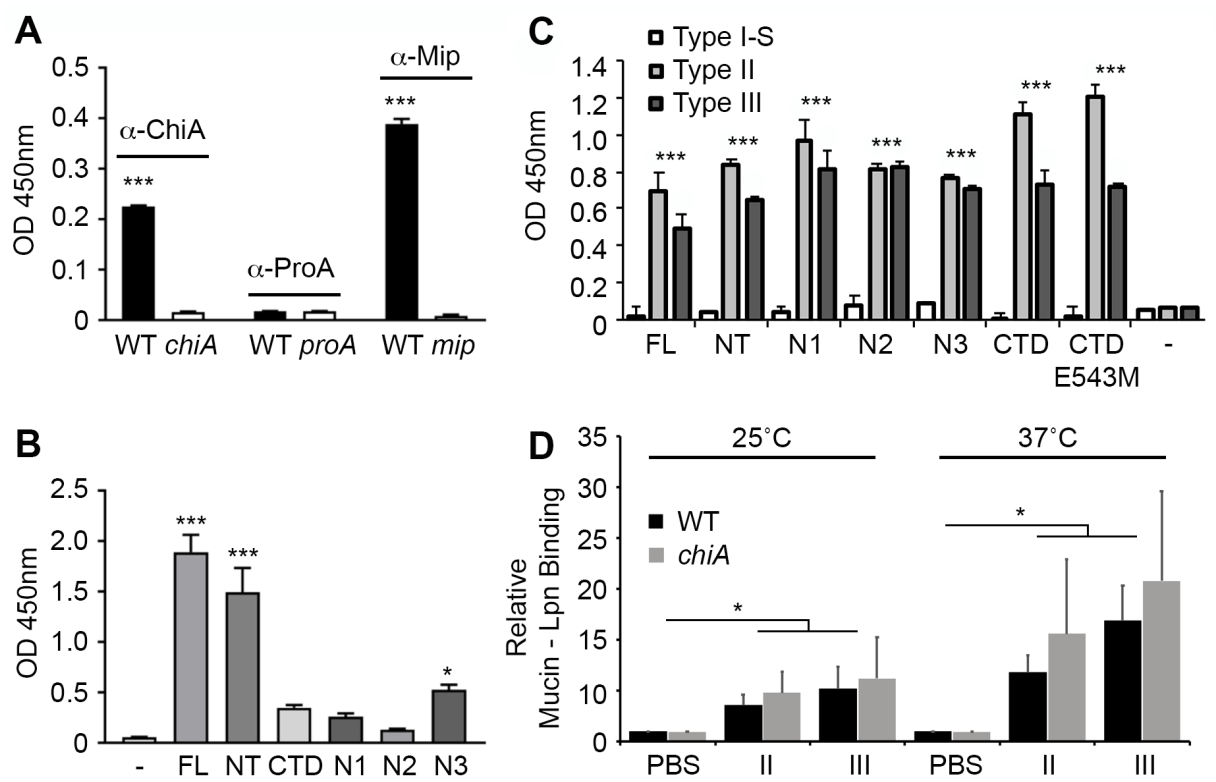

Figure 4: L. pneumophila surface association of ChiA and mucin binding. (A) Whole cell ELISA of L. pneumophila wild-type 130b (WT), chiA mutant NU318 (chiA), proA mutant AA200 (proA) and mip mutant NU203 (mip) detected with antiserum specific for either ChiA, ProA, or Mip. (B) Whole cell ELISA of chiA mutant incubated with either recombinant ChiA-FL or subdomains (NT, N1, N2, N3, CTD) and detected with antiserum specific for either ChiA, ProA, or Mip. PBS buffer alone was used as a control (-). Multiple comparisons against the control were made using a one-way ANOVA, Holm-Š́lák multiple comparisons test; $* P<0.05, * * * P<0.001$. (C) ELISA analysis of binding between immobilised type I-S, II or III porcine stomach mucins and His-tagged ChiA-FL and subdomains (NT, N1, N2, N3, CTD, CTD $^{\mathrm{E} 543 \mathrm{M}}$ ) detected with anti-His-tag antibody. BSA-coated wells were used as controls. *** $P<0.001$; verses control empty well by two-tailed Student's test. (D) Mucin binding to GFP-expressing L. pneumophila WT or chiA mutant strains were incubated at $25^{\circ} \mathrm{C}$ or $37^{\circ} \mathrm{C}$ with PBS, type II or III porcine stomach mucins followed by Texas Red-tagged wheat germ agglutinin (WGA). Mucin binding to bacteria was quantified by flow cytometry. ${ }^{*} P<0.05$; verses PBS control by two-tailed Student's test. All data represent the mean and standard deviation for triplicate experiments. 


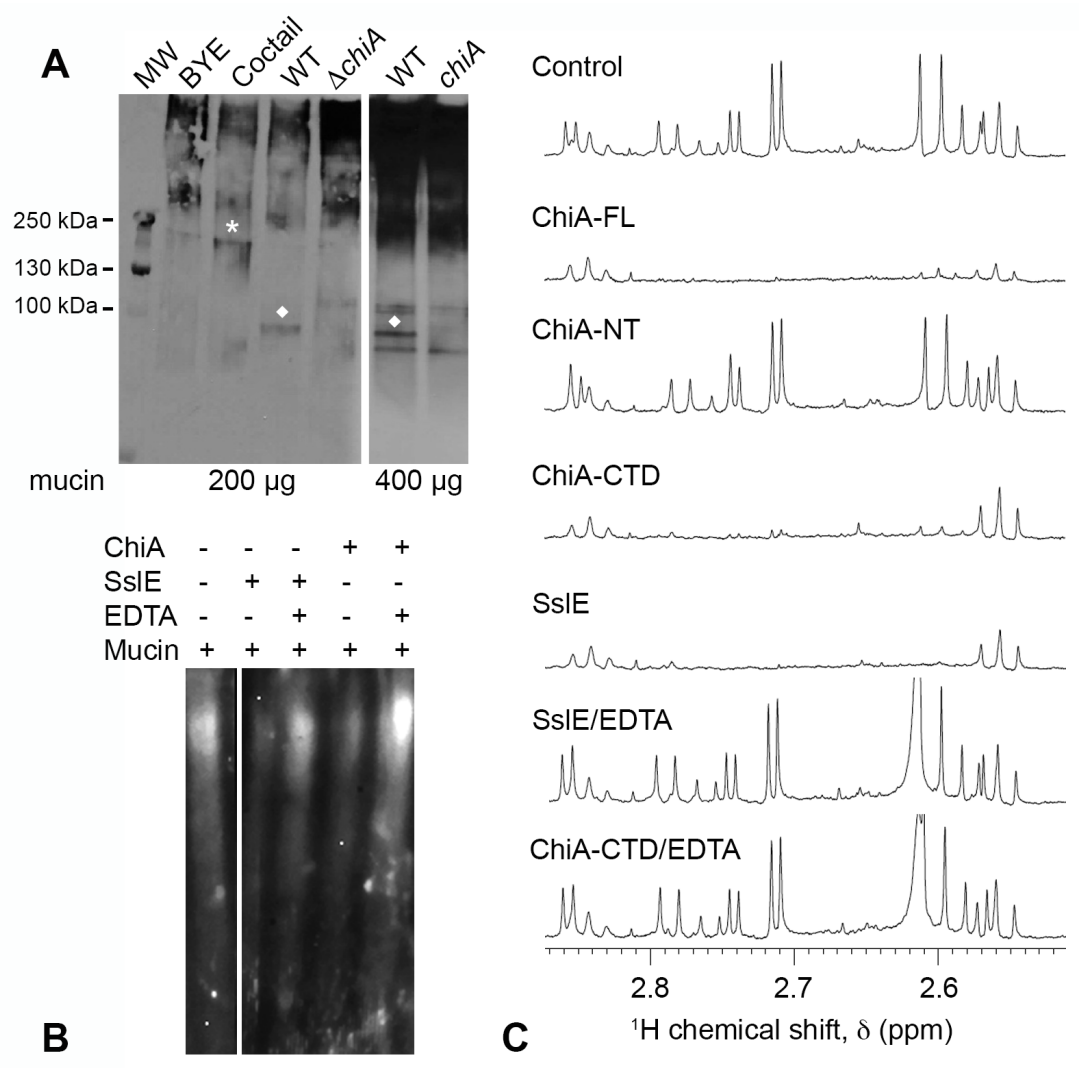

Figure 5: Mucinase activity of ChiA. (A) Secreted mucinase activity of $L$. pneumophila wild-type and chiA mutant strains. Immunoblot of type II porcine stomach mucins ( $200 \mu \mathrm{g}$ or $400 \mu \mathrm{g})$ incubated with either BYE medium alone (BYE), a cocktail of known mucinase enzymes added to BYE medium (cocktail), or supernatants from BYE cultures of wild-type 130b (WT) or chiA mutant NU318 (chiA). Asterisk highlights a lower-MW mucin species generated by the cocktail, while diamonds denote an $\sim 100 \mathrm{kDa}$ mucin species generated by the WT but not mutant supernatants. The data presented are representative of three independent experiments. (B) Immunoblot of type II porcine stomach mucin extract incubated with either ChiA-FL or SslE +/- EDTA or buffer alone. (C) 1D ${ }^{1} \mathrm{H}$ NMR spectra between $\sim 2.5$ to $\sim 2.9 \mathrm{ppm}$ is shown for type II mucin extract incubated with ChiA-FL, ChiA-NT, ChiACTD and SslE +/- EDTA or buffer alone. 


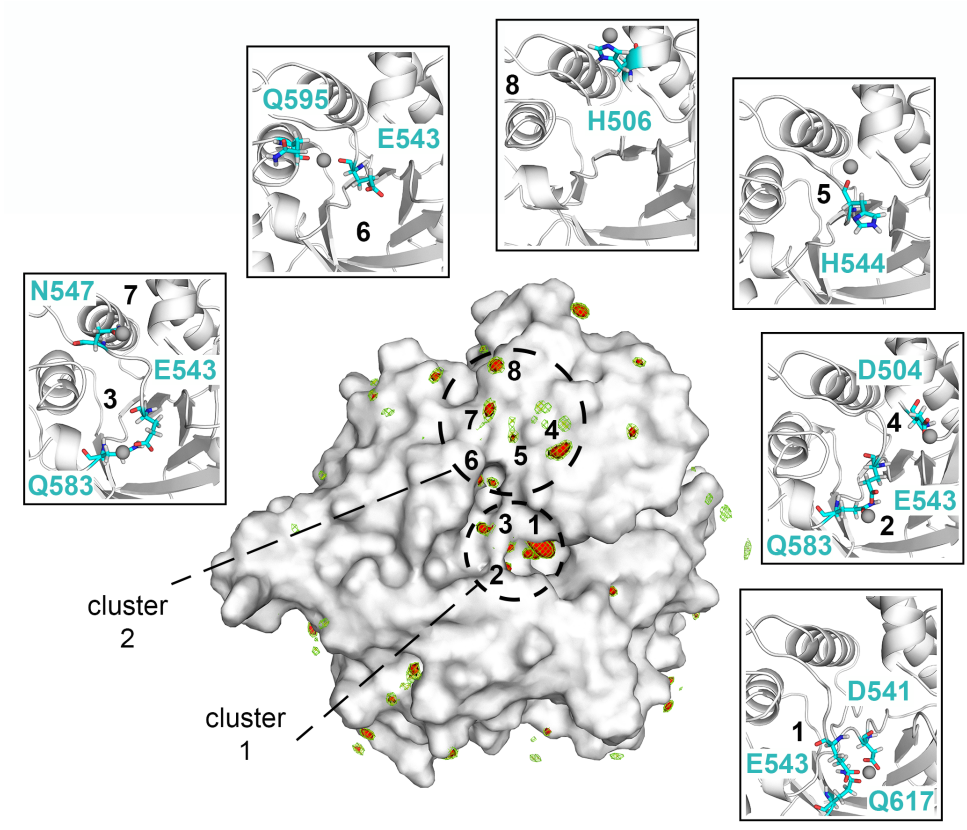

Figure 6: ChiA-CTD $\mathbf{Z n}^{2+}$ binding sites. Surface representation of ChiA-CTD showing the spatial distribution of $\mathrm{Zn}^{2+}$ ions during MD simulations. The sdf is represented with isosurfaces connecting points with $\mathrm{sdf}=20$ (green mesh), 25 (yellow mesh) and 30 (red surface) x average sdf. $\mathrm{Zn}^{2+}$ highdensity sites (red surface) around the chitinase and peptidase active sites are numbered 1 to 8 . Blow out boxes show representative structures from the MD simulations to illustrate $\mathrm{Zn}^{2+}$ binding in the eight regions, with $\mathrm{Zn}^{2+}$ ions shown as spheres, their coordinating residues as sticks and ChiA-CTD as cartoon. 
A

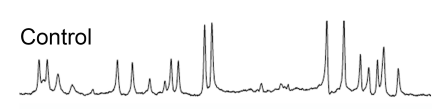

WT
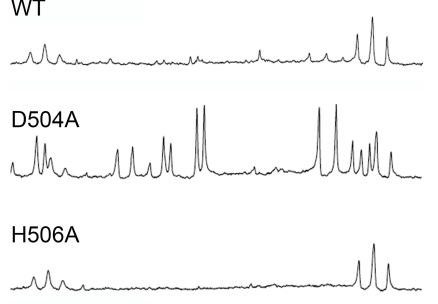

E543M
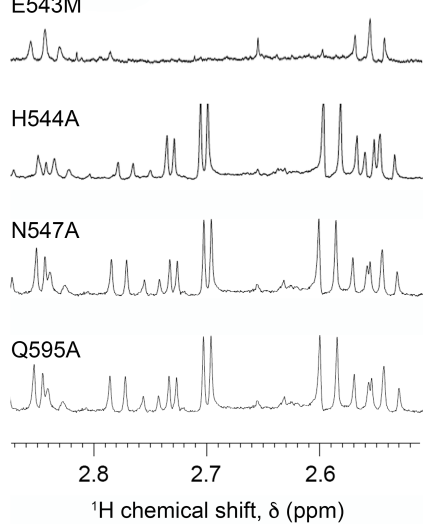

B

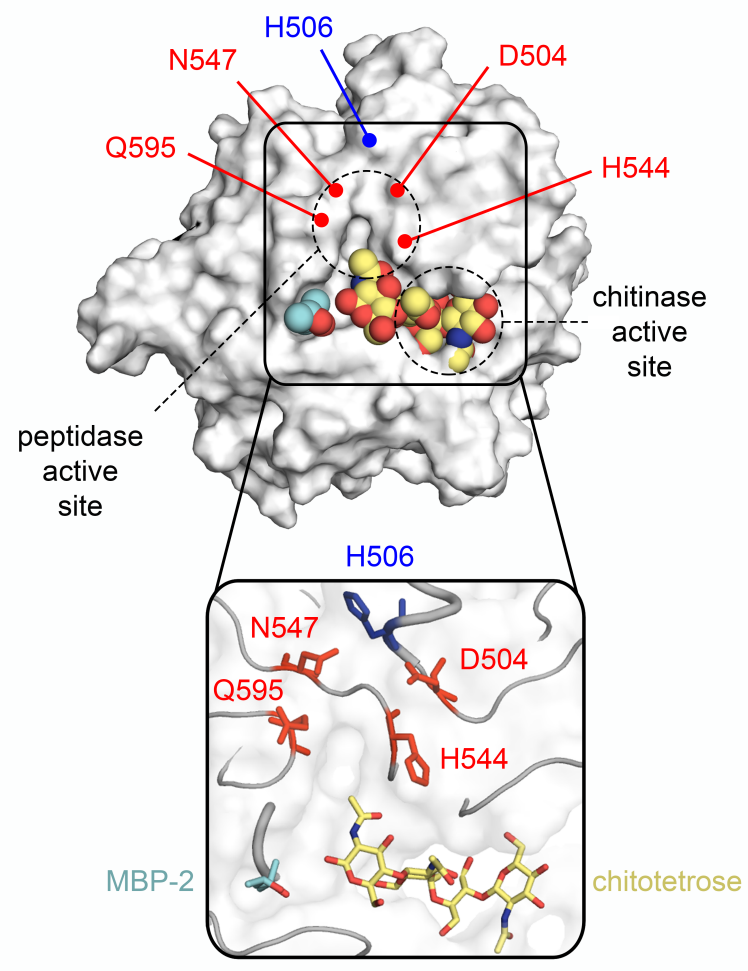

Figure 7: Peptidase active site of ChiA. (A) $1 \mathrm{D}{ }^{1} \mathrm{H}$ NMR spectra between $\sim 2.5$ to $\sim 2.9 \mathrm{ppm}$ is shown for type II porcine stomach mucins incubated with ChiA-CTD, ChiA-CTD mutants (D504A, H506A, E543M, H455A, N547A, Q595A) or buffer alone. (B) Surface and cartoon representation of ChiA-CTD bound to MPD-2 (cyan; spheres and sticks) and modelled chitotetrose (yellow; spheres and sticks), highlighting the potential for mucin branched glycan recognition. Residues that form the metaldependent aminopeptidase active site are highlighted in red. 


\section{Supplementary Figures}
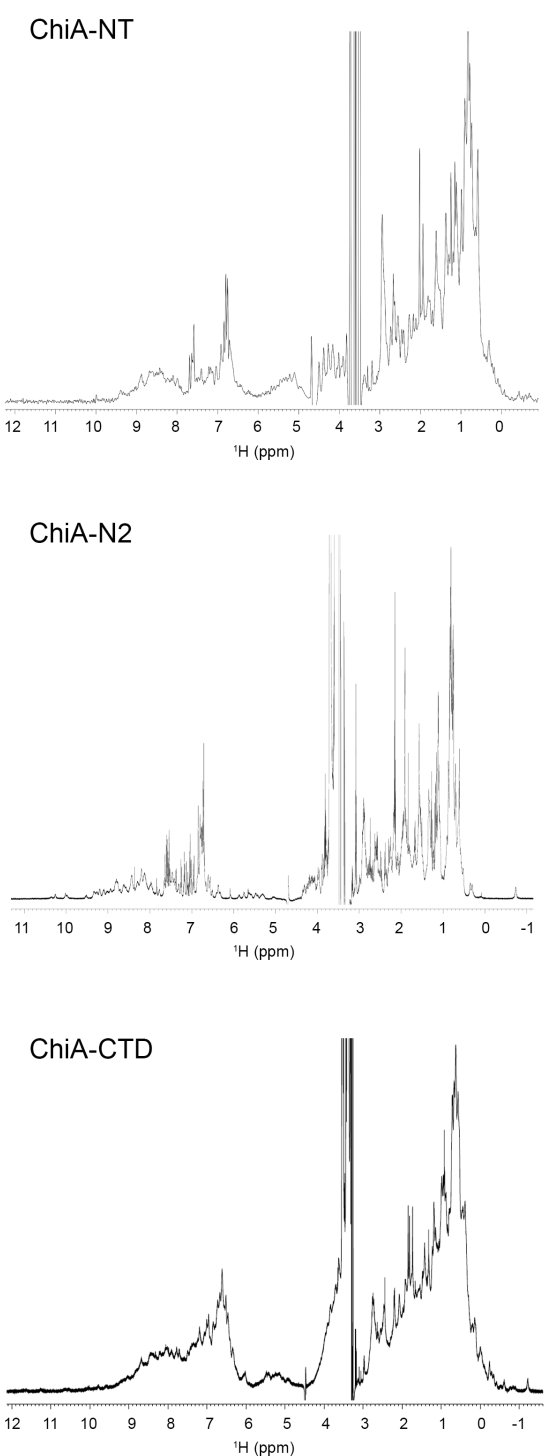

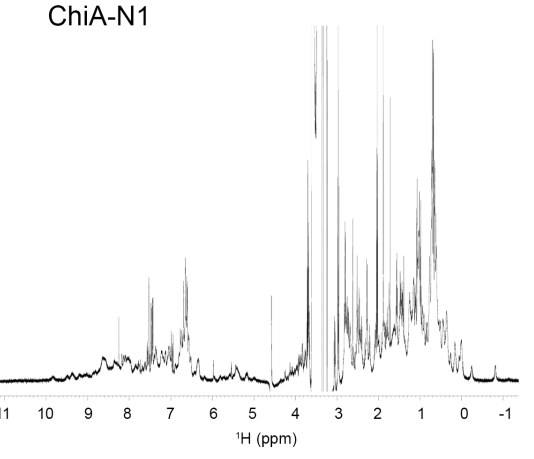

ChiA-N3

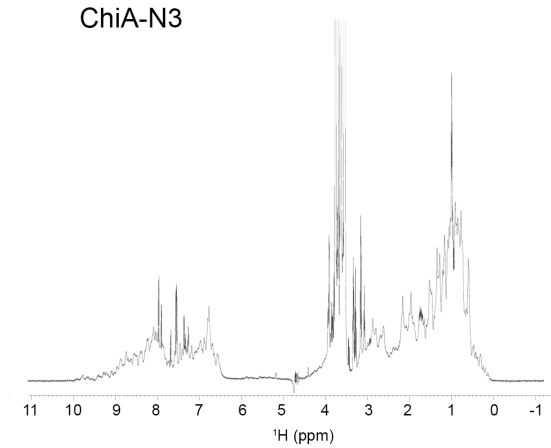

Figure S1: 1D ${ }^{1} \mathbf{H}$ NMR spectra of ChiA subdomains. The methyl region of the NMR spectra includes high-field proton resonances observed at low chemical shifts $(<0.5 \mathrm{ppm})$, which indicate the presence of characteristic clusters of aromatic and methyl groups in the core of a structured protein. In addition, the envelope of peaks resonating at high chemical shift ( $>8.5 \mathrm{ppm})$ correspond to highly ordered backbone amides present in secondary structure elements. 


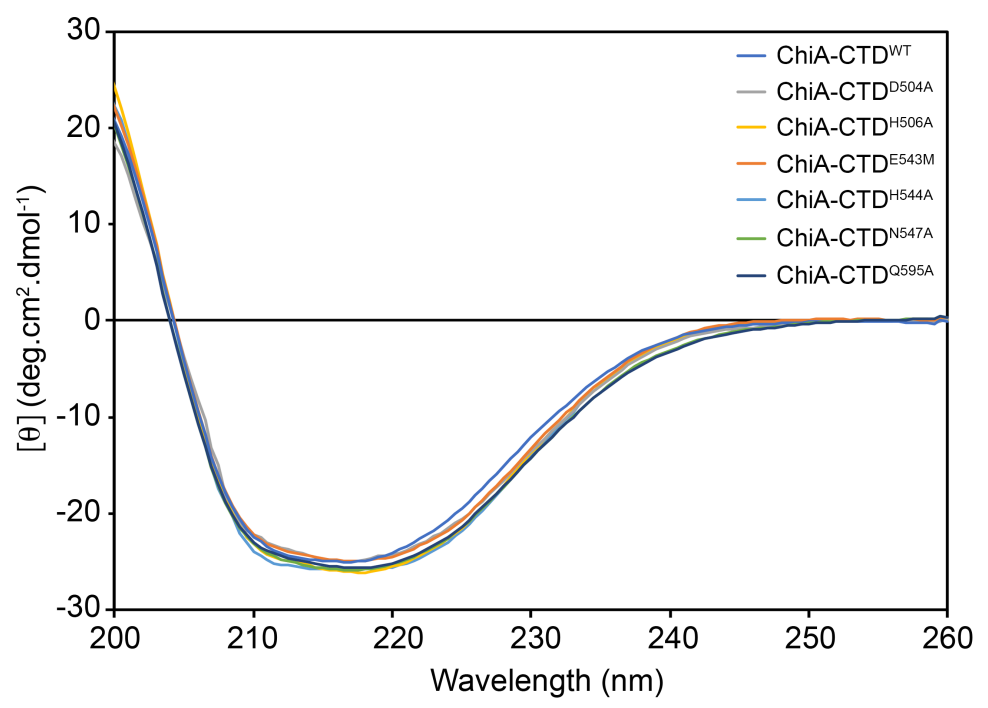

Figure S2: Circular dichroism (CD) spectra of ChiA-CTD constructs. The negative bands between $\sim 210$ to $\sim 220 \mathrm{~nm}$ and positive band at $200 \mathrm{~nm}$ is indicative of a mixed $\alpha / \beta$ protein fold. The spectra for wild type (WT) ChiA-CTD and mutants are in essence identical and demonstrates that these mutations do not perturb the structure of the CTD domain.

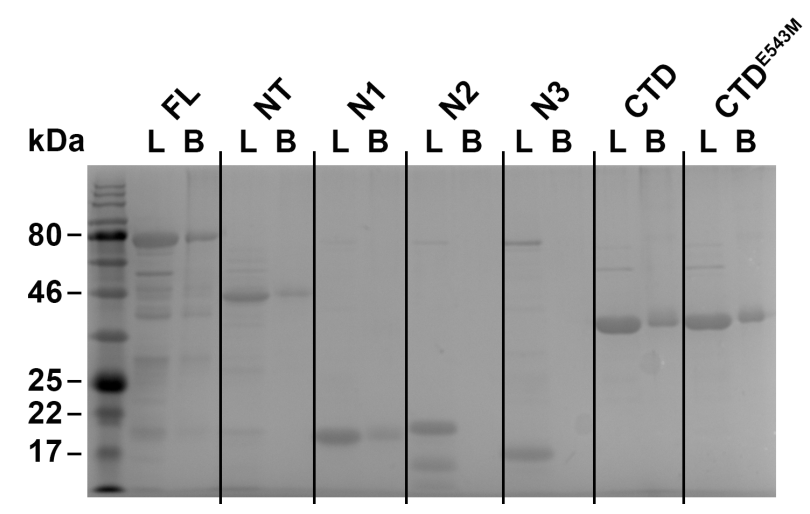

Figure S3: Chitin-resin pull down with ChiA fragments. SDS-PAGE gels loaded with ChiA and subdomains or BSA control either before incubation with chitin beads (L) or after elution from the beads (B). 


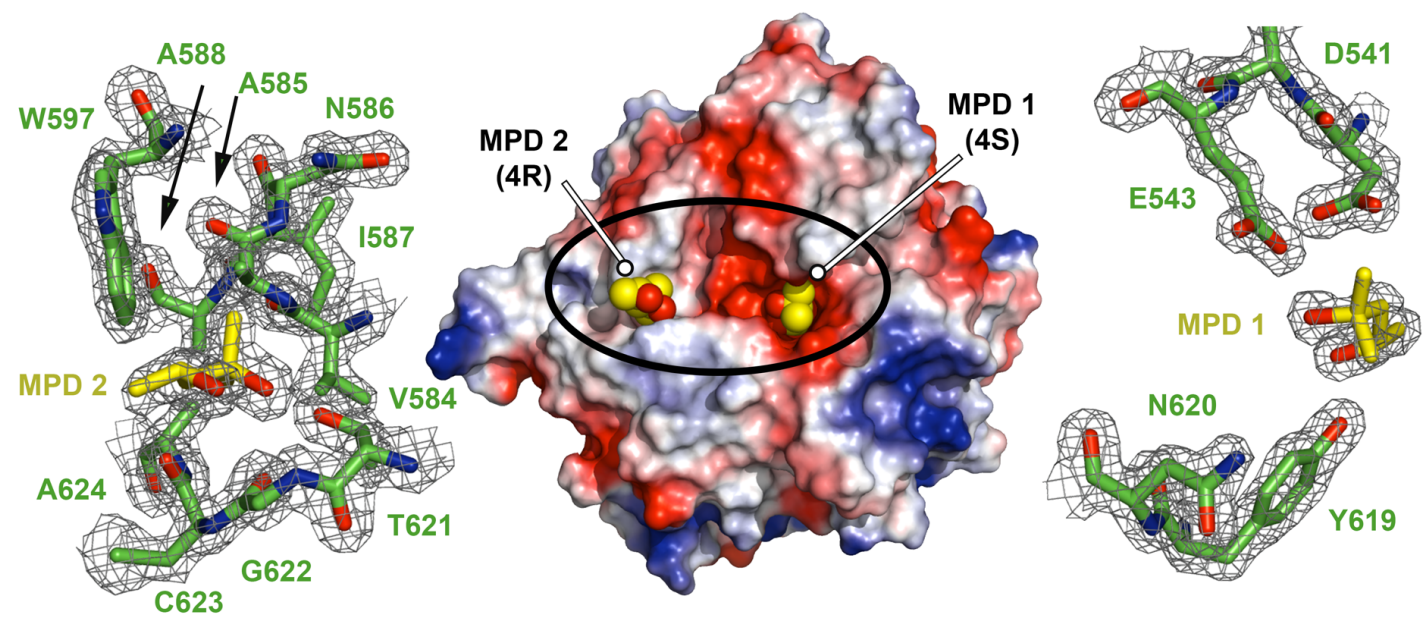

Figure S4: MPD bound to ChiA-CTD. Electrostatic surface potential representation of ChiA-CTD with two molecules of MPD shown as spheres (MPD1: 4S enantiomer; MPD2: 4R enantiomer). Each binding site is expanded and the $\sigma \mathrm{A}$ weighted electron density maps contoured at 1.0 r.m.s. are shown. 


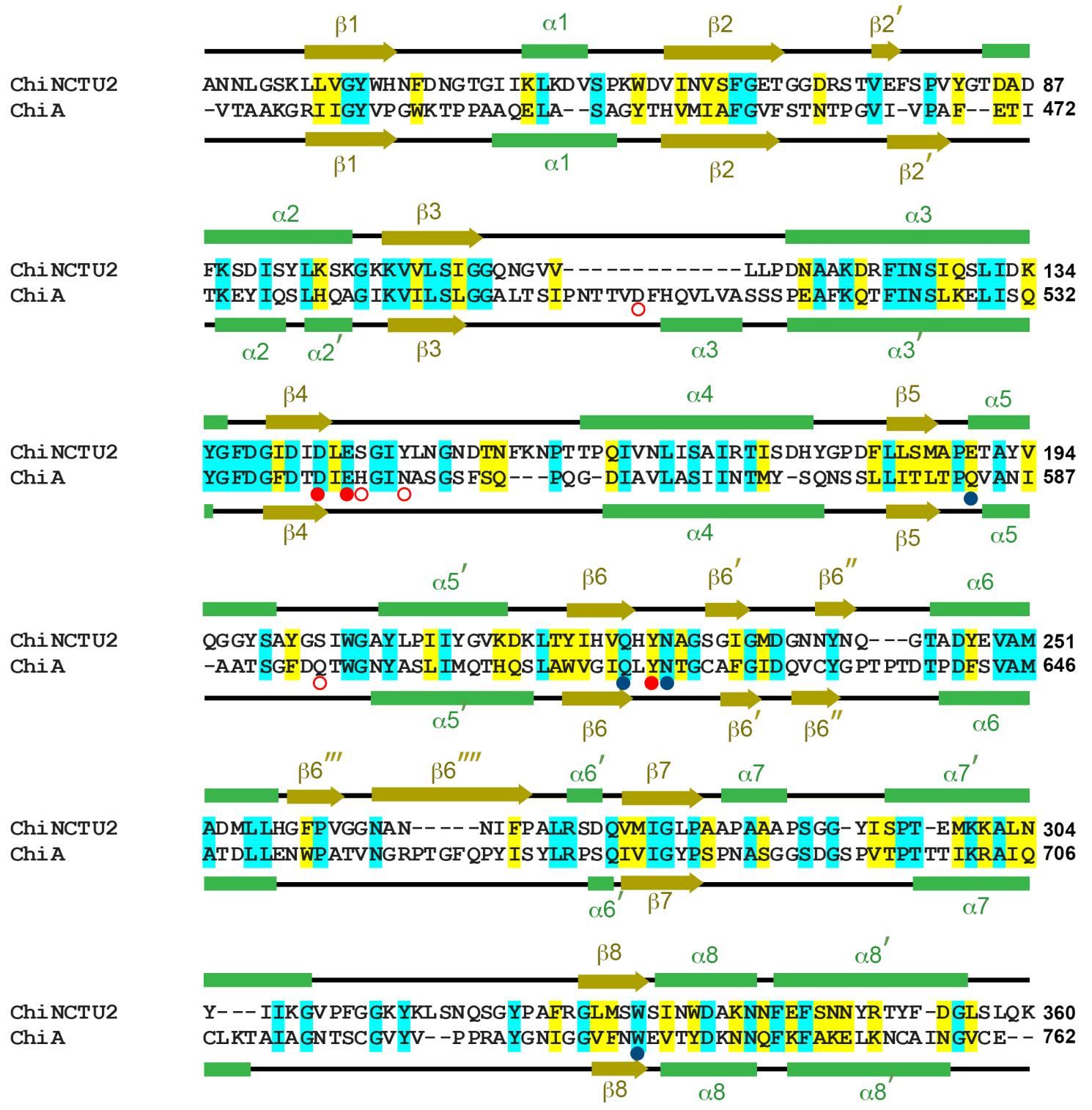

Figure S5: Sequence alignment of Legionella pneumophila ChiA-CTD and Bacillus cereus ChiNCTU2. Secondary structure elements of ChiNCTU2 and ChiA-CTD are shown above and below, respectively (green rectangle: $\alpha$-helix; gold arrow: $\beta$-strand). Amino acid identities and similar residues are indicated by background shading in cyan and yellow, respectively. Catalytic chitinase residues and chitin binding residues in ChiNCTU2 are indicated with red and blue filled circles, respectively. Mucinase active site residues in ChiA-CTD are shown as open red circles. 


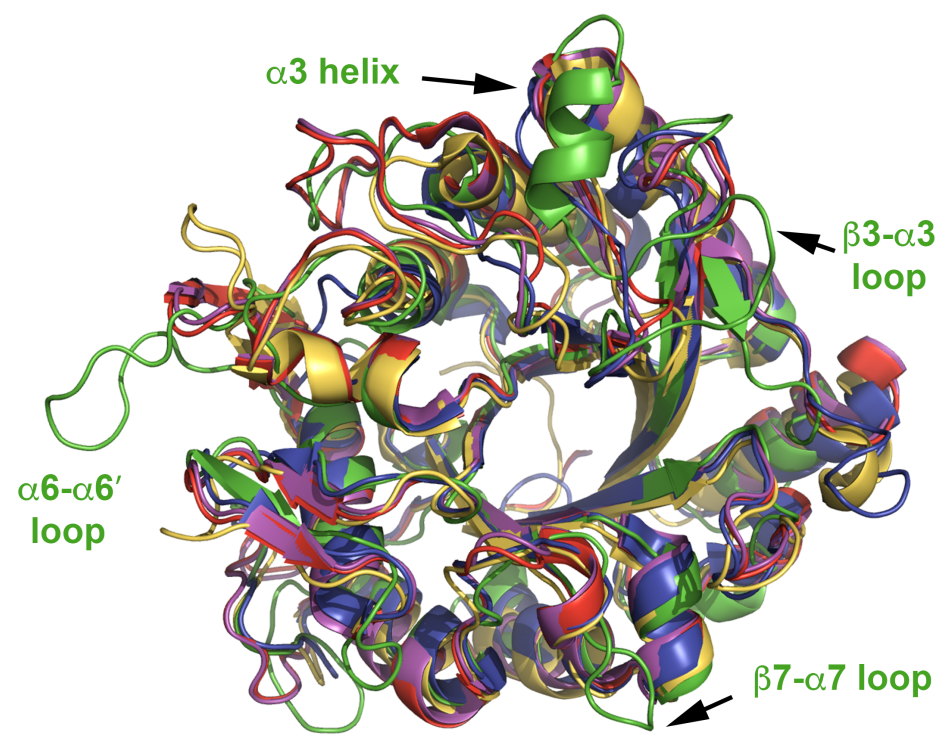

Figure S6: Superposition of ChiA-CTD tertiary homologs. L. pneumophila ChiA-CTD is green, Bacillus cereus ChiNCTU2 is purple (PDB ID code 3n18) (45), Bacillus anthracis Chi36 is red (PDB ID code 5kz6, Chromobacterium violaceum ChiA is yellow (PDB ID code 4tx8) and Streptomyces coelicolor ChiA is blue (PDB ID code 3ebv). Augmented loop and helical structures in L. pneumophila ChiA-CTD are annotated.

A

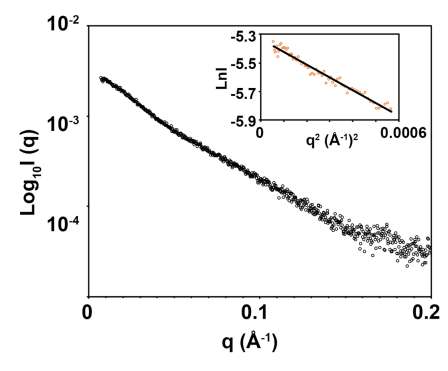

D
B

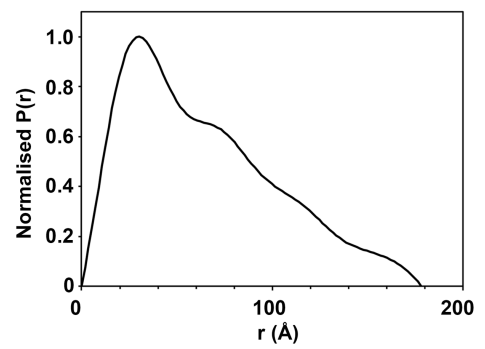

C

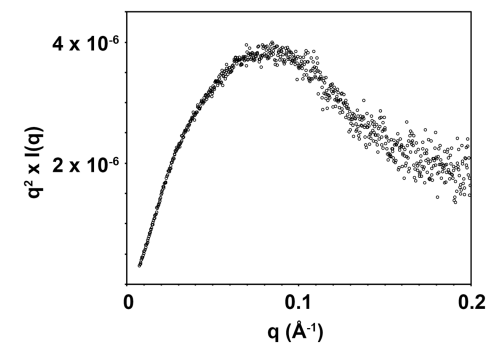

E
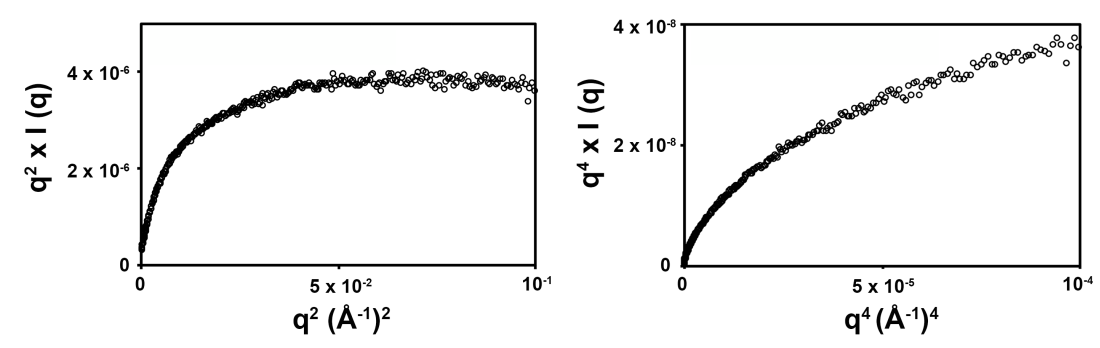

Figure S7: SAXS analysis of ChiA-FL. (A) Experimental scattering curve of ChiA-FL (black open circles). Inset: Guinier Region (orange open circles) and linear regression (black line) for Rg evaluation. (B) Shape distribution [P(r)] function derived from SAXS analysis for ChiA. (C) Kratky, (D) KratkyDebye and (E) Porod-Debye plots indicate that ChiA is a highly dynamic particle in solution. 


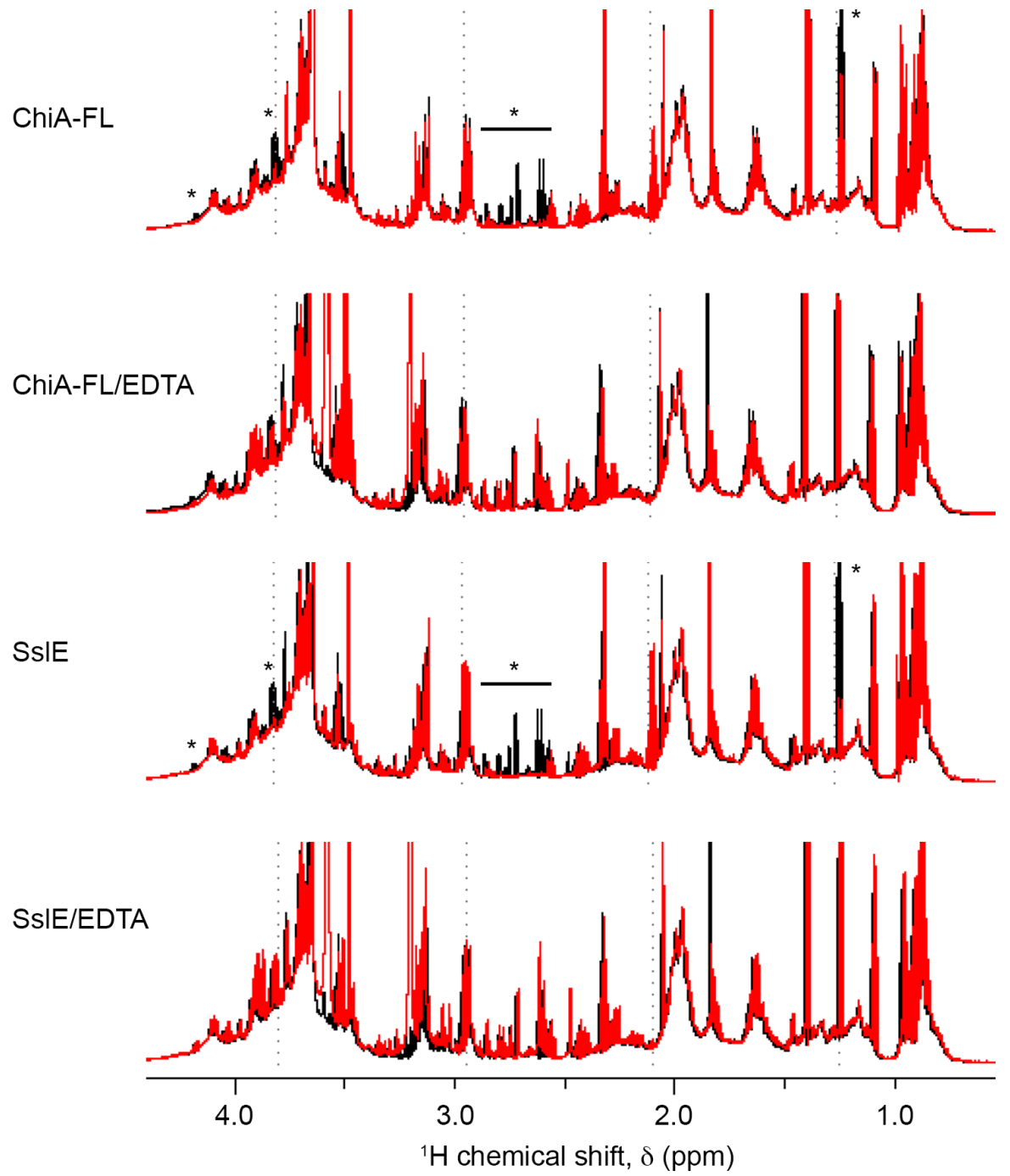

Figure S8. 1D ${ }^{1} \mathrm{H}$ NMR spectra showing mucinase activity of ChiA. Type II mucin extract incubated at $24^{\circ} \mathrm{C}$ for $12 \mathrm{hrs}$ (black) is compared to type II mucin extract with either full length ChiA (ChiA-FL), ChiA-FL and EDTA, SslE or SslE and EDTA incubated at $24^{\circ} \mathrm{C}$ for $12 \mathrm{hrs}$ (red). The region between $\sim 0.5$ and $4.5 \mathrm{ppm}$ is shown and significant differences between the spectra are highlighted with an asterisk. 


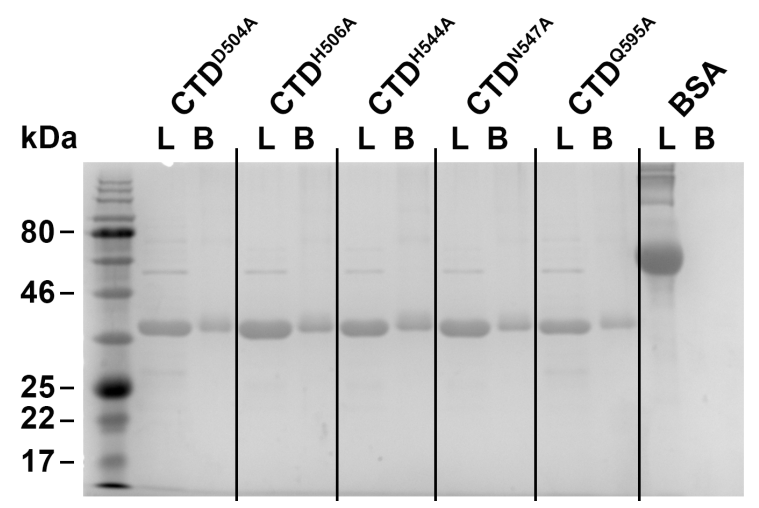

Figure S9: Chitin-resin pull down with ChiA mutants. SDS-PAGE gels loaded with ChiA-CTD mutants or BSA control either before incubation with chitin beads (L) or after elution from the beads (B).

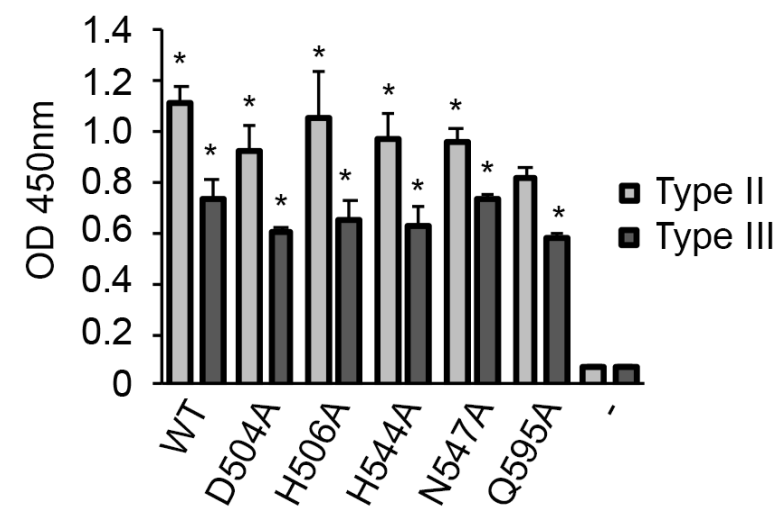

Figure S10: Mucin binding of ChiA-CTD mutants. (A) ELISA analysis of binding between immobilised type II or III mucin extracts and His-tagged wild-type ChiA-CTD (WT) and ChiA-CTD mutants (D504A, H506A, H544A, N547A, Q595A). Anti-His-tag antibody conjugated to HRP was used to measure $\mathrm{OD}_{450} \mathrm{~nm}$ values. BSA-coated wells were used as controls. Data represent the mean and standard deviation for triplicate experiments. ${ }^{*}, P<0.001$; verses control empty well by two-tailed Student's test. 


\section{Supplementary Tables}

Table S1: Tertiary structure predictions of ChiA N-terminal subdomains

\begin{tabular}{|c|c|c|c|c|c|c|c|}
\hline $\begin{array}{c}\text { ChiA } \\
\text { domain }\end{array}$ & $\begin{array}{l}\text { Protein } \\
\text { Name }\end{array}$ & Organism & Function & $\begin{array}{l}\text { Sequence } \\
\text { identity }\end{array}$ & $\begin{array}{l}\text { PDB } \\
\text { code }\end{array}$ & Ref & $\begin{array}{l}\text { Prediction } \\
\text { server }\end{array}$ \\
\hline N1 & RsgI2 & $\begin{array}{l}\text { Clostridium } \\
\text { thermocellum }\end{array}$ & $\begin{array}{l}\text { Putative cellulosomal } \\
\text { family } 3 \text { carbohydrate } \\
\text { binding module }\end{array}$ & $16 \%$ & 4B9P & $(46)$ & Phyre2/Robetta \\
\hline N1 & ScaA & $\begin{array}{l}\text { Acetivibrio } \\
\text { Cellulolyticus }\end{array}$ & $\begin{array}{l}\text { Family 3B carbohydrate } \\
\text { binding module - binds } \\
\text { strongly to cellulose }\end{array}$ & $21 \%$ & 3ZQW & (47) & Phyre2 \\
\hline N1 & CipC & $\begin{array}{l}\text { Clostridium } \\
\text { cellulolyticum }\end{array}$ & $\begin{array}{l}\text { Family } 3 \text { A carbohydrate } \\
\text { binding module - binds } \\
\text { strongly to cellulose }\end{array}$ & $20 \%$ & $1 \mathrm{G} 43$ & (48) & Phyre2 \\
\hline N1 & $\begin{array}{l}\text { Endo- } \\
\text { glucanase D }\end{array}$ & $\begin{array}{l}\text { Clostridium } \\
\text { cellulovorans }\end{array}$ & $\begin{array}{l}\text { C-terminal carbohydrate } \\
\text { binding module }\end{array}$ & $17 \%$ & $3 \mathrm{NDY}$ & N/A & Phyre2 \\
\hline N1 & Chil8aC & $\begin{array}{l}\text { Streptomyces } \\
\text { coelicolor }\end{array}$ & $\begin{array}{l}\text { Chitinase chitin binding } \\
\text { domain }\end{array}$ & $18 \%$ & 2RTT & N/A & Phyre2 \\
\hline N1 & RsgI3 & $\begin{array}{l}\text { Clostridium } \\
\text { thermocellum }\end{array}$ & $\begin{array}{l}\text { Putative cellulosomal } \\
\text { family } 3 \text { carbohydrate } \\
\text { binding module }\end{array}$ & $14 \%$ & 4B97 & $(46)$ & Phyre2 \\
\hline N1 & CBDcex & $\begin{array}{l}\text { Cellulomonas } \\
\text { fimi }\end{array}$ & $\begin{array}{l}\text { Cellulose carbohydrate } \\
\text { binding module }\end{array}$ & $19 \%$ & $1 \mathrm{EXH}$ & (49) & Phyre2 \\
\hline $\mathrm{N} 2$ & RG-lyase & $\begin{array}{l}\text { Aspergillus } \\
\text { aculeatus }\end{array}$ & $\begin{array}{l}\text { Rhamnogalacturonan } \\
\text { lyase fibronectin type III } \\
\text { domain }\end{array}$ & $19 \%$ & $1 \mathrm{NKG}$ & $(50)$ & Phyre2 \\
\hline $\mathrm{N} 2$ & CbhA & $\begin{array}{l}\text { Clostridium } \\
\text { thermocellum }\end{array}$ & $\begin{array}{l}\text { Cellobiohydrolase A } \\
\text { fibronectin type III } \\
\text { domain }\end{array}$ & $16 \%$ & $\begin{array}{l}\text { 3PE9/ } \\
\text { 3PDG }\end{array}$ & $(51)$ & Phyre2 \\
\hline $\mathrm{N} 2$ & Tenascin & Chicken & $\begin{array}{l}\text { Tandem fibronectin type } \\
\text { III domains }\end{array}$ & $12 \%$ & 1QR4 & $(52)$ & Robetta \\
\hline N3 & ChiA & $\begin{array}{l}\text { Autographa } \\
\text { californica } \\
\text { nuclear } \\
\text { polyhedrosis } \\
\text { virus }\end{array}$ & $\begin{array}{l}\text { N-terminal chitinase } \\
\text { domain - chitin binding }\end{array}$ & $15 \%$ & $5 \mathrm{DF} 0$ & N/A & Phyre2 \\
\hline
\end{tabular}




\section{Table S2: Diffraction data and refinement statistics}

\begin{tabular}{|c|c|c|}
\hline & Native & Iodide \\
\hline \multicolumn{3}{|l|}{ Crystal Parameters } \\
\hline Space group & $C 2$ & $C 2$ \\
\hline Cell dimensions $\left(\AA ;{ }^{\circ}\right)$ & $\begin{array}{l}a=97.37, b=56.64, \\
c=128.96 ; \beta=93.79\end{array}$ & $\begin{array}{l}a=97.25, b=57.35, \\
c=129.42 ; \beta=93.43\end{array}$ \\
\hline \multicolumn{3}{|l|}{ Data collection } \\
\hline Beamline & DLS I04 & DLS I02 \\
\hline Wavelength $(\AA)$ & 0.97949 & 1.70000 \\
\hline Resolution $(\AA)$ & $\begin{array}{l}64.34-1.71 \\
(1.75-1.71)\end{array}$ & $\begin{array}{r}64.59-1.89 \\
(1.94-1.89) \\
\end{array}$ \\
\hline Unique observations & $75905(5555)$ & $52043(2309)$ \\
\hline $\mathrm{R}_{\text {sym }}$ & $0.061(0.658)$ & $0.189(3.697)$ \\
\hline$<I>/ \sigma I$ & $19.2(2.8)$ & $9.7(1.4)$ \\
\hline Completeness (\%) & $99.9(99.9)$ & $91.2(55.0)$ \\
\hline Redundancy & $6.8(6.9)$ & $13.1(11.4)$ \\
\hline \multicolumn{3}{|l|}{ Phasing } \\
\hline Figure of merit (accentric/centric) & $0.159 / 0.139$ & - \\
\hline Phasing power isotropic (accentric/centric) & $1.059 / 0.919$ & - \\
\hline Phasing power anomalous & 0.887 & \\
\hline \multicolumn{3}{|l|}{ Refinement } \\
\hline $\mathrm{R}_{\mathrm{work}} / \mathrm{R}_{\text {free }}(\%)$ & $14.5 / 16.7$ & - \\
\hline Number of protein residues & 678 & - \\
\hline Number of water molecules & 669 & - \\
\hline Number of ligands & 2 MPD, 2 MRD & - \\
\hline \multicolumn{3}{|l|}{ rmsd stereochemistry } \\
\hline Bond lengths $(\AA)$ & 0.012 & - \\
\hline Bond angles $\left({ }^{\circ}\right)$ & 1.534 & - \\
\hline \multicolumn{3}{|l|}{ Ramachandran analysis } \\
\hline Residues in outlier regions (\%) & 0.0 & - \\
\hline Residues in favoured regions (\%) & 96.6 & - \\
\hline Residues in allowed regions (\%) & 100 & - \\
\hline
\end{tabular}

Numbers in parentheses refer to the outermost resolution shell.

$R_{\mathrm{sym}}=\sum|I-\langle I\rangle| / \sum I$ where $I$ is the integrated intensity of a given reflection and $\langle I>$ is the mean intensity of multiple corresponding symmetry-related reflections.

$R_{\text {work }}=\sum|| \mathrm{F}_{\mathrm{o}}|-| \mathrm{F}_{\mathrm{c}} \mid / \sum \mathrm{F}_{\mathrm{o}}$ where $\mathrm{F}_{\mathrm{o}}$ and $\mathrm{F}_{\mathrm{c}}$ are the observed and calculated structure factors, respectively.

$R_{\text {free }}=R_{\text {work }}$ calculated using $10 \%$ random data excluded from the refinement.

rmsd stereochemistry is the deviation from ideal values.

Ramachandran analysis was carried out using Molprobity (53).

Table S3: SAXS structural parameters

\begin{tabular}{|l|l|l|}
\hline \multicolumn{2}{|l|}{ SAXS data collection } & \\
\hline & Beamline & DLS B21 \\
\hline & Wavelength $(\AA)$ & 1.0 \\
\hline & q Range $\left(\AA^{-1}\right)$ & 0.004 to 0.4 \\
\hline & Concentration range $(\mathrm{mg} / \mathrm{mL})$ & 0.5 to 4 \\
\hline Structural parameters & \\
\hline & $\mathrm{I}(0)$ & $5.36 \mathrm{e}-03 \pm 2.6 \mathrm{e}-05$ \\
\hline & $\mathrm{R}_{\mathrm{g}}(\mathrm{nm})$ (from Guinier) & $5.43 \pm 0.05$ \\
\hline & $\mathrm{R}_{\mathrm{g}}(\mathrm{nm})($ from $\mathrm{P}(\mathrm{r}))$ & $5.45 \pm 0.03$ \\
\hline & $\mathrm{D}_{\max }(\mathrm{nm})($ from $\mathrm{P}(\mathrm{r}))$ & 17.77 \\
\hline & $\mathrm{MW}(\mathrm{kDa})$ (from sequence) & 82.6 \\
\hline & $\mathrm{MW}(\mathrm{kDa})$ (from SAXS) & 89.2 \\
\hline
\end{tabular}


Table S4: SAXS ensemble optimization parameters

\begin{tabular}{|c|c|c|c|c|}
\hline & Run 1 & Run 2 & Run 3 & Average \\
\hline $\mathrm{R}_{\text {flex }}($ random) & $90.47(89.14)$ & $91.60(89.70)$ & $92.14(89.72)$ & $91.4(89.5)$ \\
\hline $\mathrm{R}_{\text {sig }}$ & 1.22 & 1.22 & 1.25 & 1.23 \\
\hline$\chi^{2}$ & 1.07 & 1.05 & 1.14 & 1.09 \\
\hline Cluster 1 (\%) & 17.2 & 19.3 & 18.2 & 18.2 \\
\hline Cluster 2 (\%) & 49.4 & 40.6 & 46.4 & 45.5 \\
\hline Cluster 3 (\%) & 33.4 & 40.1 & 35.4 & 36.3 \\
\hline Final ensemble $\mathrm{R}_{\mathrm{g}}(\mathrm{nm})$ & 5.40 & 5.43 & 5.39 & 5.41 \\
\hline Final ensemble $\mathrm{D}_{\max }(\mathrm{nm})$ & 17.11 & 17.28 & 16.73 & 17.04 \\
\hline
\end{tabular}

Table S5: Primers used in this study

\begin{tabular}{|c|c|c|}
\hline Primer & Description & Sequence ( $5^{\prime}$ to $\left.3^{\prime}\right)$ \\
\hline JG9 & ChiA-FL F & GACGACGACAAGATGAATACCTCTTTAAAACCCTCAATTGCC \\
\hline JG10 & ChiA-FL R & GAGGAGAAGCCCGGTTACTCACAAACACCATTAATAGCACAATTTTTC \\
\hline JG9 & ChiA-NT F & GACGACGACAAGATGAATACCTCTTTAAAACCCTCAATTGCC \\
\hline JG11 & ChiA-NT R & GAGGAGAAGCCCGGTTAAGATAAAGTGATGTTTACTGTTGCATTTTC \\
\hline JG9 & ChiA-N1 F & GACGACGACAAGATGAATACCTCTTTAAAACCCTCAATTGCC \\
\hline JG12 & ChiA-N1 R & GAGGAGAAGCCCGGTTAGATGCTTCCTGATTCAACCGTTG \\
\hline JG13 & ChiA-N2 F & GACGACGACAAGATGGGAAGCATCCAATTAATCAATGCTGC \\
\hline JG14 & ChiA-N2 R & GAGGAGAAGCCCGGTTAATCGTTATATTGAATTGCAGGAGTTGAG \\
\hline JG15 & ChiA-N3 F & GACGACGACAAGATGGGGAGTAGTTACCAATTCTCAACTC \\
\hline JG11 & ChiA-N3 R & GAGGAGAAGCCCGGTTAAGATAAAGTGATGTTTACTGTTGCATTTTC \\
\hline JG16 & ChiA-CTD F & GACGACGACAAGATGGTAACCGCTGCAAAAGGGC \\
\hline JG10 & ChiA-CTD R & GAGGAGAAGCCCGGTTACTCACAAACACCATTAATAGCACAATTTTTC \\
\hline JG17 & $\begin{array}{l}\text { ChiA-CTD } \\
\text { E543M mutant F }\end{array}$ & $\begin{array}{l}\text { AGGAGTTAATTTCTCAATATGGTTTTGATGGGTTTGATACAGATATTATGCAT } \\
\text { GGTATTAACGCTAGCGG }\end{array}$ \\
\hline JG18 & $\begin{array}{l}\text { ChiA-CTD } \\
\text { E543M mutant R }\end{array}$ & $\begin{array}{l}\text { CCGCTAGCGTTAATACCATGCATAATATCTGTATCAAACCCATCAAAACCATA } \\
\text { TTGAGAAATTAACTCCT }\end{array}$ \\
\hline PC1 & SslE F & AGGAGATATACCATGAGCTACCCGCTCAACTATATG \\
\hline $\mathrm{PC} 2$ & SslE R & GTGATGGTGATGTTTCTCGACAGACATCTTATGC \\
\hline
\end{tabular}


bioRxiv preprint doi: https://doi.org/10.1101/687871; this version posted July 2, 2019. The copyright holder for this preprint (which was not certified by peer review) is the author/funder. All rights reserved. No reuse allowed without permission.

Table S6: Synthetic genes

\begin{tabular}{|c|c|c|}
\hline Gene & Description & Sequence (5' to $\left.3^{\prime}\right)$ \\
\hline CM4 & $\begin{array}{l}\text { ChiA-CTD } \\
\text { D504A } \\
\text { mutant }\end{array}$ & $\begin{array}{l}\text { CCATGGTCCATCATCATCATCATCATGTGGACGACGACGACAAGATGGTTACCGCAGCAAAAGG } \\
\text { TCGCATTATTGGTTATGTTCCAGGTTGGAAAACCCCTCCGCAGCACAAGAACTGGCAAGCGCA } \\
\text { GGTTATACCCATGTTATGATTGCATTTGGTGTGTTCAGCACCAATACACCGGGTGTTATTGTTC } \\
\text { CGGCATTTGAAACATTACCAAAGAGTATTCAGAGCCTGCATCAGGCAGGCATTAAAGTAT } \\
\text { TCTGAGCTTAGGTGGTGCACTGACCAGCATTCCGAATACCACCGTTCGTTCATCAGGTTCTG } \\
\text { GTTGCAAGCAGCAGTCCGGAAGCATTTAAACAGACCTTTATTAACAGCCTGAAAGAACTGATTA } \\
\text { GCCAGTATGGTTTGATGGCTTTATACCGATATTATGCATGGTATTAATGCCAGCGGTAGCTT } \\
\text { TAGCCAGCCGCAGGGTGATATTGCAGTTCTGGCAAGCATTATTAACACCATGTATAGCCAGAAT } \\
\text { AGCAGCCTGCTGATTACCCTGACACCGCAGGTTGCAAATATTGCAGCAACCAGCGGTTTTGATC } \\
\text { AGACCTGGGGAATTATGCAAGCCTGATTATGCAGACCCATCAGAGTCTGGCATGGGTTGGAT } \\
\text { TCAGCTGTATAATACCGTTGTGCCTTTGGTATTGATCAGGTTTGTTATGGTCCGACACCGACC } \\
\text { GATACACCGGATTTTAGCGTTGCAATGGCAACCGATCTGCTGGAAAATTGGCCTGCAACCGTTA } \\
\text { ATGGTCGTCCGACCGGTTTCAGCCGTATATTAGCTATCTGCGTCCGAGCCAGATTGTGATTGG } \\
\text { TTATCCGAGTCCGATGCAAGCGGGGTAGTGATGGTAGTCCGGTACACCGACCACCACCATT } \\
\text { AAACGTGCAATTCAGTGTCTGAAAACAGCCATTGCAGGTAATACCAGCTGTGGTGTTTATGTTC } \\
\text { CGCCTCGTGCATATGGTAATATTGGTGGTGTTTTAATTGGGAAGTGACCTACGATAAAAACAA } \\
\text { CCAGTTCAAATTCGCCAAAGAGCTGAAAAATTGCGCGATTAATGGCGTGTTGAATAACTCGAG }\end{array}$ \\
\hline
\end{tabular}

CM5 ChiA-CTD CCATGGTCCATCATCATCATCATCATGTGGACGACGACGACAAGATGGTTACCGCAGCAAAAGG H506A TCGCATTATTGGTTATGTTCCAGGTTGGAAAACCCCTCCGGCAGCACAAGAACTGGCAAGCGCA mutant GGTTATACCCATGTTATGATTGCATTTGGTGTGTTCAGCACCAATACACCGGGTGTTATTGTTC CGGCATTTGAAACCATTACCAAAGAGTATATTCAGAGCCTGCATCAGGCAGGCATTAAAGTTAT TCTGAGCTTAGGTGGTGCACTGACCAGCATTCCGAATACCACCGTTGATTTTGCGCAGGTTCTG GTTGCAAGCAGCAGTCCGGAAGCATTTAAACAGACCTTTATTAACAGCCTGAAAGAACTGATTA GCCAGTATGGTTTTGATGGCTTTGATACCGATATTATGCATGGTATTAATGCCAGCGGTAGCTT TAGCCAGCCGCAGGGTGATATTGCAGTTCTGGCAAGCATTATTAACACCATGTATAGCCAGAAT AGCAGCCTGCTGATTACCCTGACACCGCAGGTTGCAAATATTGCAGCAACCAGCGGTTTTGATC AGACCTGGGGTAATTATGCAAGCCTGATTATGCAGACCCATCAGAGTCTGGCATGGGTTGGTAT TCAGCTGTATAATACCGGTTGTGCCTTTGGTATTGATCAGGTTTGTTATGGTCCGACACCGACC GATACACCGGATTTTAGCGTTGCAATGGCAACCGATCTGCTGGAAAATTGGCCTGCAACCGTTA ATGGTCGTCCGACCGGTTTTCAGCCGTATATTAGCTATCTGCGTCCGAGCCAGATTGTGATTGG TTATCCGAGTCCGAATGCAAGCGGTGGTAGTGATGGTAGTCCGGTTACACCGACCACCACCATT AAACGTGCAATTCAGTGTCTGAAAACAGCCATTGCAGGTAATACCAGCTGTGGTGTTTATGTTC CGCCTCGTGCATATGGTAATATTGGTGGTGTGTTTAATTGGGAAGTGACCTACGATAAAAACAA CCAGTTCAAATTCGCCAAAGAGCTGAAAAATTGCGCGATTAATGGCGTGTGTGAATAACTCGAG

CM6 ChiA-CTD

H544A

mutant

CCATGGTCCATCATCATCATCATCATGTGGACGACGACGACAAGATGGTTACCGCAGCAAAAGG TCGCATTATTGGTTATGTTCCAGGTTGGAAAACCCCTCCGGCAGCACAAGAACTGGCAAGCGCA GGTTATACCCATGTTATGATTGCATTTGGTGTGTTCAGCACCAATACACCGGGTGTTATTGTTC CGGCATTTGAAACCATTACCAAAGAGTATATTCAGAGCCTGCATCAGGCAGGCATTAAAGTTAT TCTGAGCTTAGGTGGTGCACTGACCAGCATTCCGAATACCACCGTTGATTTTCATCAGGTTCTG GTTGCAAGCAGCAGTCCGGAAGCATTTAAACAGACCTTTATTAACAGCCTGAAAGAACTGATTA GCCAGTATGGTTTTGATGGCTTTGATACCGATATTATGGCGGGTATTAATGCCAGCGGTAGCTT TAGCCAGCCGCAGGGTGATATTGCAGTTCTGGCAAGCATTATTAACACCATGTATAGCCAGAAT AGCAGCCTGCTGATTACCCTGACACCGCAGGTTGCAAATATTGCAGCAACCAGCGGTTTTGATC AGACCTGGGGTAATTATGCAAGCCTGATTATGCAGACCCATCAGAGTCTGGCATGGGTTGGTAT TCAGCTGTATAATACCGGTTGTGCCTTTGGTATTGATCAGGTTTGTTATGGTCCGACACCGACC GATACACCGGATTTTAGCGTTGCAATGGCAACCGATCTGCTGGAAAATTGGCCTGCAACCGTTA ATGGTCGTCCGACCGGTTTTCAGCCGTATATTAGCTATCTGCGTCCGAGCCAGATTGTGATTGG TTATCCGAGTCCGAATGCAAGCGGTGGTAGTGATGGTAGTCCGGTTACACCGACCACCACCATT AAACGTGCAATTCAGTGTCTGAAAACAGCCATTGCAGGTAATACCAGCTGTGGTGTTTATGTTC CGCCTCGTGCATATGGTAATATTGGTGGTGTGTTTAATTGGGAAGTGACCTACGATAAAAACAA CCAGTTCAAATTCGCCAAAGAGCTGAAAAATTGCGCGATTAATGGCGTGTGTGAATAACTCGAG

CM7 ChiA-CTD CCATGGTCCATCATCATCATCATCATGTGGACGACGACGACAAGATGGTTACCGCAGCAAAAGG N547A mutant TCGCATTATTGGTTATGTTCCAGGTTGGAAAACCCCTCCGGCAGCACAAGAACTGGCAAGCGCA GGTTATACCCATGTTATGATTGCATTTGGTGTGTTCAGCACCAATACACCGGGTGTTATTGTTC CGGCATTTGAAACCATTACCAAAGAGTATATTCAGAGCCTGCATCAGGCAGGCATTAAAGTTAT TCTGAGCTTAGGTGGTGCACTGACCAGCATTCCGAATACCACCGTTGATTTTCATCAGGTTCTG GTTGCAAGCAGCAGTCCGGAAGCATTTAAACAGACCTTTATTAACAGCCTGAAAGAACTGATTA GCCAGTATGGTTTTGATGGCTTTGATACCGATATTATGCATGGTATTGCGGCCAGCGGTAGCTT TAGCCAGCCGCAGGGTGATATTGCAGTTCTGGCAAGCATTATTAACACCATGTATAGCCAGAAT AGCAGCCTGCTGATTACCCTGACACCGCAGGTTGCAAATATTGCAGCAACCAGCGGTTTTGATC AGACCTGGGGTAATTATGCAAGCCTGATTATGCAGACCCATCAGAGTCTGGCATGGGTTGGTAT TCAGCTGTATAATACCGGTTGTGCCTTTGGTATTGATCAGGTTTGTTATGGTCCGACACCGACC GATACACCGGATTTTAGCGTTGCAATGGCAACCGATCTGCTGGAAAATTGGCCTGCAACCGTTA 
bioRxiv preprint doi: https://doi.org/10.1101/687871; this version posted July 2, 2019. The copyright holder for this preprint (which was not certified by peer review) is the author/funder. All rights reserved. No reuse allowed without permission.

\begin{abstract}
ATGGTCGTCCGACCGGTTTTCAGCCGTATATTAGCTATCTGCGTCCGAGCCAGATTGTGATTGG TTATCCGAGTCCGAATGCAAGCGGTGGTAGTGATGGTAGTCCGGTTACACCGACCACCACCATT AAACGTGCAATTCAGTGTCTGAAAACAGCCATTGCAGGTAATACCAGCTGTGGTGTTTATGTTC CGCCTCGTGCATATGGTAATATTGGTGGTGTGTTTAATTGGGAAGTGACCTACGATAAAAACAA CCAGTTCAAATTCGCCAAAGAGCTGAAAAATTGCGCGATTAATGGCGTGTGTGAATAACTCGAG
\end{abstract}

CM8 ChiA-CTD CCATGGTCCATCATCATCATCATCATGTGGACGACGACGACAAGATGGTTACCGCAGCAAAAGg Q595A TCGCATTATTGGTTATGTTCCAGGTTGGAAAACCCCTCCGGCAGCACAAGAACTGGCAAGCGCA mutant GGTTATACCCATGTTATGATTGCATTTGGTGTGTTCAGCACCAATACACCGGGTGTTATTGTTC CGGCATTTGAAACCATTACCAAAGAGTATATTCAGAGCCTGCATCAGGCAGGCATTAAAGTTAT TCTGAGCTTAGGTGGTGCACTGACCAGCATTCCGAATACCACCGTTGATTTTCATCAGGTTCTG GTTGCAAGCAGCAGTCCGGAAGCATTTAAACAGACCTTTATTAACAGCCTGAAAGAACTGATTA GCCAGTATGGTTTTGATGGCTTTGATACCGATATTATGCATGGTATTAATGCCAGCGGTAGCTT TAGCCAGCCGCAGGGTGATATTGCAGTTCTGGCAAGCATTATTAACACCATGTATAGCCAGAAT AGCAGCCTGCTGATTACCCTGACACCGCAGGTTGCAAATATTGCAGCAACCAGCGGTTTTGATG CGACCTGGGGTAATTATGCAAGCCTGATTATGCAGACCCATCAGAGTCTGGCATGGGTTGGTAT TCAGCTGTATAATACCGGTTGTGCCTTTGGTATTGATCAGGTTTGTTATGGTCCGACACCGACC GATACACCGGATTTTAGCGTTGCAATGGCAACCGATCTGCTGGAAAATTGGCCTGCAACCGTTA ATGGTCGTCCGACCGGTTTTCAGCCGTATATTAGCTATCTGCGTCCGAGCCAGATTGTGATTGG TTATCCGAGTCCGAATGCAAGCGGTGGTAGTGATGGTAGTCCGGTTACACCGACCACCACCATT AAACGTGCAATTCAGTGTCTGAAAACAGCCATTGCAGGTAATACCAGCTGTGGTGTTTATGTTC CGCCTCGTGCATATGGTAATATTGGTGGTGTGTTTAATTGGGAAGTGACCTACGATAAAAACAA CCAGTTCAAATTCGCCAAAGAGCTGAAAAATTGCGCGATTAATGGCGTGTGTGAATAACTCGAG

*Restriction sites are underlined 


\section{Methods}

Cloning, expression and purification - Full-length ChiA (ChiA-FL; residues 1-762), minus the Nterminal periplasmic signal sequence, the ChiA N-terminal region (ChiA-NT; residues 1-417), the ChiA N1-domain (ChiA-N1; residues 1-140), the ChiA N2-domain (ChiA-N2; residues 138-299), the ChiA N3-domain (ChiA-N3; residues 285-417) and the ChiA C-domain (ChiA-CTD; residues 419-762) were amplified from the genomic DNA of L. pneumophila strain $130 \mathrm{~b}$ and cloned into the N-terminal His $6^{-}$ tagged vector pET-46 Ek/LIC (Table S5). SslE (residues 90-1520), minus the N-terminal periplasmic signal sequence and mature SslE N-terminal proline-rich region, were amplified from the genomic DNA of $E$. coli strain W and cloned into the C-terminal His6-tagged vector pOPINE (Table S5). These were transformed into E. coli SHuffle cells (New England Biolabs) and grown at $37^{\circ} \mathrm{C}$ in $\mathrm{LB}$ media with $100 \mu \mathrm{g} / \mathrm{ml}$ ampicillin. Expression was induced with $1 \mathrm{mM}$ isopropyl-d-1-thiogalactopyranoside (IPTG) at an $\mathrm{OD}_{600 \mathrm{~nm}}$ of 0.6 and cells were harvested after growth overnight at $18^{\circ} \mathrm{C}$. Cells were resuspended in $20 \mathrm{mM}$ Tris- $\mathrm{HCl} \mathrm{pH} \mathrm{8,} 200 \mathrm{mM} \mathrm{NaCl}, 5 \mathrm{mM} \mathrm{MgCl} 2,1 \mathrm{mg} / \mathrm{ml} \mathrm{DNase} \mathrm{I,} 5 \mathrm{mg} / \mathrm{ml}$ lysozyme, lysed by sonication and purified using nickel affinity chromatography. All samples were then gel filtered using a Superdex 200 column (GE Healthcare) equilibrated in $20 \mathrm{mM}$ Tris- $\mathrm{HCl} \mathrm{pH} \mathrm{8,} 200$ $\mathrm{mM} \mathrm{NaCl}$.

Nuclear magnetic resonance spectroscopy - One-dimensional proton NMR experiments were performed at $25^{\circ} \mathrm{C}$ on $300 \mu \mathrm{M}$ ChiA-NT, ChiA-N1, ChiA-N2, ChiA-N3 and ChiA-CTD samples in a buffer containing $20 \mathrm{mM}$ Tris- $\mathrm{HCl} \mathrm{pH} 8.0,100 \mathrm{mM} \mathrm{NaCl}, 10 \% \mathrm{D}_{2} \mathrm{O}$. Spectra were recorded on a Bruker Avance III 700 MHz (ChiA-N1, ChiA-N2, ChiA-N3, ChiA-CTD) or $800 \mathrm{MHz}$ (ChiA-NT) spectrometer equipped with cryoprobes and processed within TopSpin (Bruker).

Site-directed mutagenesis - E543M chiA-CTD mutant was created using pET46chiA-CTD template DNA with a QuikChange II Site-Directed Mutagenesis Kit (Stratagene) (Table S5). D504A, H506A, H544A, N547A and Q595A chiA-CTD mutants were synthesized by Synbio Technologies and cloned into $\mathrm{pET} 28 \mathrm{~b}$ vector using NcoI and XhoI restriction sites (Table S6). All resulting clones were verified by DNA sequencing and then expressed and purified as described for wild-type ChiA-CTD.

Circular dichroism - Far-UV CD spectra were measured in a Chirascan (Applied Photophysics) spectropolarimeter thermostated at $20^{\circ} \mathrm{C}$. Spectra for wild-type ChiA-CTD and ChiA-CTD ${ }^{\mathrm{E} 543 \mathrm{M}}$, ChiA$\mathrm{CTD}^{\mathrm{D} 504 \mathrm{~A}}$, ChiA-CTD ${ }^{\mathrm{H} 506 \mathrm{~A}}$, ChiA-CTD ${ }^{\mathrm{H} 544 \mathrm{~A}}$, ChiA-CTD ${ }^{\mathrm{N} 547 \mathrm{~A}}$ and ChiA-CTD ${ }^{\text {Q595A }}$ mutants $(0.05$ $\mathrm{mg} / \mathrm{ml}$ ) in $10 \mathrm{mM}$ Tris- $\mathrm{HCl} \mathrm{pH} 8.0,100 \mathrm{mM} \mathrm{NaCl}$ were recorded from 260 to $200 \mathrm{~nm}$, at $0.5 \mathrm{~nm}$ intervals, $1 \mathrm{~nm}$ bandwidth, and a scan speed of $10 \mathrm{~nm} / \mathrm{min}$. Three accumulations were averaged for each spectrum. 
Chitinase activity assay - Enzyme activity was determined using 4-Nitrophenol $\beta-\mathrm{D}-\mathrm{N}, \mathrm{N}$ ', N"'triacetylchitotriose (Sigma) as a substrate. $10 \mu$ of ChiA-FL, ChiA-NT, ChiA-CTD, ChiA-CTD ${ }^{\mathrm{E} 543 \mathrm{M}}$ at $10 \mu \mathrm{g} / \mathrm{ml}$ in PBS were incubated with $90 \mu \mathrm{l}$ of substrate at $0.4 \mathrm{mg} / \mathrm{ml}$ dissolved in Sigma buffer (A4855, pH 5.0) (Sigma) at $37^{\circ} \mathrm{C}$ for $30 \mathrm{~min}$. The reaction was quenched by adding $200 \mu \mathrm{l}$ of $100 \mathrm{mM}$ sodium carbonate. Absorbance at $405 \mathrm{~nm}$ was measured and corrected for absorption in a control sample with added PBS instead of protein.

Chitin binding assay - $250 \mu$ ChiA-FL, ChiA-NT, ChiA-N1, ChiA-N2, ChiA-N3, ChiA-CTD, ChiA$\mathrm{CTD}^{\mathrm{D} 504 \mathrm{~A}}$, ChiA-CTD ${ }^{\mathrm{H} 506 \mathrm{~A}}$, ChiA-CTD ${ }^{\mathrm{E} 543 \mathrm{M}}$, ChiA-CTD ${ }^{\mathrm{H} 544 \mathrm{~A}}$, ChiA-CTD ${ }^{\mathrm{N} 547 \mathrm{~A}}$, ChiA-CTD ${ }^{\text {Q595A }}$ and BSA (Sigma) at $10 \mu \mathrm{M}$ in $20 \mathrm{mM}$ Tris- $\mathrm{HCl}$ pH 8.0, $200 \mathrm{mM} \mathrm{NaCl}$ were incubated with $50 \mu 1$ chitinresin (Sigma) and incubated whilst shaking for $30 \mathrm{~min}$. The resin was washed three times with $500 \mu 1$ of the same buffer and then proteins were eluted by incubating the resin in $250 \mu \mathrm{l}$ of $8 \mathrm{M}$ urea, $1 \%$ (w/v) SDS for 30 min whilst shaking. Protein samples prior to incubation with chitin-resin and the eluted protein/chitin-resin slurry were then analysed with SDS-PAGE.

Crystal structure determination - Crystallization of ChiA CTD-domain $(30 \mathrm{mg} / \mathrm{ml})$ was performed using the sitting-drop vapour-diffusion method grown in $0.2 \mathrm{M}$ ammonium acetate, $0.1 \mathrm{M}$ Bis-Tris $\mathrm{pH}$ 5.5, 45\% (v/v) 2-Methyl-2,4-pentanediol at 293K. Native crystals were flash cooled in liquid nitrogen and diffraction data were collected at $100 \mathrm{~K}$ on beamline I04 at the Diamond Light Source (DLS), UK. Crystals were also soaked for $1 \mathrm{~min}$ in well solution containing 1.0 M NaI, flash cooled in liquid nitrogen and data were collected at 100K on beamline I02 at the Diamond Light Source (DLS), UK. Data were processed with XDS (54) and scaled with AIMLESS (55) using the XIA2 pipeline (56). The structure of ChiA CTD-domain was determined with I-SIRAS. Twenty-one iodide sites were located in ChiA C-domain using SHELXD (57), and then phases were calculated using autoSHARP (58). After automated model building with ARP/wARP (59), the remaining structure was manually built within Coot (60). Refinement was carried out with REFMAC (61) using non-crystallographic symmetry (NCS) and translation-libration-screw (TLS) groups $(62,63)$, and $5 \%$ of the reflections were omitted for crossvalidation. Processing and refinement statistics of the final model can be found in Table S2. The coordinates and structure factors have been deposited in the PDB under ID code $6 \mathrm{~s} 2 \mathrm{x}$.

SAXS data collection and analysis - SAXS data were collected on beamline B21 at the Diamond Light Source (DLS), UK at $20^{\circ} \mathrm{C}$. Full-length ChiA in $20 \mathrm{mM}$ Tris- $\mathrm{HCl}$ pH 8, $200 \mathrm{mM} \mathrm{NaCl}$ were measured at $4,2,1$ and $0.5 \mathrm{mg} / \mathrm{ml}$ concentrations, after gel filtration using a Superdex 200 column (GE Healthcare), over a momentum transfer range of $0.004<q<0.4 \AA^{-1}$. A fresh sample of BSA was measured as a standard. Buffer subtraction, intensity normalization, and data merging for the different sample concentrations were performed in SCATTER (DLS, UK). ChiA data collected above $1 \mathrm{mg} / \mathrm{ml}$ showed signs of aggregation and were discarded. Further analysis was carried out with the $1 \mathrm{mg} / \mathrm{ml}$ 
data using a q range $0.008<q<0.2 \AA^{-1}$. The radius of gyration $(\mathrm{Rg})$ and scattering at zero angle $(\mathrm{I}(0))$ were calculated from the analysis of the Guinier region by AUTORG $(64,65)$. The distance distribution function $(\mathrm{P}(\mathrm{r}))$ was subsequently obtained using $\operatorname{GNOM}(64,65)$, yielding the maximum particle dimension $\left(D_{\max }\right)$. Determination of molecular model ensembles that best fit the SAXS data was performed using EOM2.0 $(66,67)$. An initial model of ChiA was created from PHYRE2 models of the N1- and N3-domains (residues 7-132; 300-399), a ROBETTA model of the N2-domain (residues 138290) and our crystal structure of the C-domain (residues 424-762), with domain linker sequences kept unstructured. SAXS structural and EOM parameters can be found in Table S3 and Table S4, respectively.

ELISA for detection of ChiA on bacterial surface - Bacterial whole-cell ELISA was done as previously described (68), with slight modification. Wild-type L. pneumophila strain $130 \mathrm{~b}$ and isogenic mutants lacking either chiA (strain NU318) (69), mip (strain NU203) (70), or proA (strain AA200) (71) were grown on $\mathrm{BCYE}$ agar for 3 days at $37^{\circ} \mathrm{C}$. Using a sterile cotton swab, bacteria were resuspended in $1 \mathrm{ml}$ sterile PBS to an $\mathrm{OD}_{660} 0.3$, centrifuged at $10,000 \times \mathrm{g}$ for $3 \mathrm{~min}$, and then washed once with PBS to remove debris and unbound proteins. Bacteria were fixed in $4 \%(\mathrm{w} / \mathrm{v})$ paraformaldehyde for 10 min, followed by two 1-ml washes in PBS. Bacteria were resuspended in coating buffer $(100 \mathrm{mM}$ bicarbonate/carbonate buffer, $\mathrm{pH}$ 9.6) to a final $\mathrm{OD}_{660} 0.03$, and $100 \mu 1$ of this suspension were added into the wells of Nunc MaxiSorp immunoassay plates (Thermo Fisher Scientific). Following overnight incubation at $4{ }^{\circ} \mathrm{C}$, the wells were washed three times with $200 \mu 1$ of wash buffer (PBS $+0.05 \%$ Tween20 ), and then $200 \mu \mathrm{l}$ of blocking buffer (PBS $+0.05 \%$ Tween-20 $+5 \%$ dried milk) were added for $1 \mathrm{~h}$ at $25^{\circ} \mathrm{C}$. After removal of the blocking buffer, samples were incubated with $100 \mu 1$ of primary antibody (i.e., rabbit anti-Mip (72), rabbit anti-ChiA (73), or rabbit anti-ProA (73) diluted 1:10,000 in blocking buffer for $1 \mathrm{~h}$ at $25^{\circ} \mathrm{C}$. Following three, $200-\mu \mathrm{l}$ washes with wash buffer, samples were incubated with $100 \mu \mathrm{l}$ of secondary antibody (anti-rabbit conjugated HRP) diluted 1:1,000 in blocking buffer for $1 \mathrm{~h}$ at $25^{\circ} \mathrm{C}$. Following five washes with $200 \mu 1$ wash buffer, samples were incubated with $100 \mu 1$ 3,3',5,5'Tetramethylbenzidine (TMB) substrate for $15 \mathrm{~min}$ at $25^{\circ} \mathrm{C}$, and then, the reaction was stopped by addition of $50 \mu \mathrm{l}$ of $2 \mathrm{~N}$ sulfuric acid. Absorbance values were measured at $450 \mathrm{~nm}$ with wavelength correction of $570 \mathrm{~nm}$ using a microplate reader (Synergy H1, BioTek). To confirm that bacterial lysis had not occurred during sample processing and plate coating, L. pneumophila-coated wells were probed with an ICDH-specific antiserum that recognizes a cytosolic L. pneumophila protein (74), and no signal was detected (data not shown). In order to assess the binding of recombinant ChiA and ChiA subdomains to the L. pneumophila surface, chiA mutant NU318 was grown on BCYE agar, washed, and resuspended in PBS, as indicated above. Prior to fixation, bacteria resuspended to $\mathrm{OD}_{660} 0.3$ were incubated with $1 \mu \mathrm{g}$ of recombinant protein in the presence of 1x protease inhibitors (Pierce, Thermo Scientific) in sterile $1.5 \mathrm{ml}$ microcentrifuge tubes with gentle end-over-end mixing for $30 \mathrm{~min}$ at $25^{\circ} \mathrm{C}$. 
Following two 1-ml washes in PBS to remove unbound protein, bacteria were fixed with $4 \%(\mathrm{w} / \mathrm{v})$ paraformaldehyde and processed for ELISA as described above. Preliminary assays determined that the polyclonal anti-ChiA (73) antiserum was capable of recognizing each of the recombinant ChiA fragments when they were added to wells in the absence of bacteria (data not shown).

Mucin binding ELISA - Immulon 2-HB 96-well plates (VWR) were coated overnight at $4^{\circ} \mathrm{C}$ with 50 $\mu \mathrm{l}$ of partially purified mucins from bovine submaxillary glands (type I-S; Sigma) and porcine stomachs (type II and III; Sigma) at $100 \mu \mathrm{g} / \mathrm{ml}$ in $50 \mathrm{mM}$ Carbonate/Bicarbonate $\mathrm{pH}$ 9.6. Wells were blocked for $1 \mathrm{hr}$ at $25^{\circ} \mathrm{C}$ with $200 \mu \mathrm{l}$ of $0.1 \%$ (w/v) bovine serum albumin (BSA) in PBS- $0.05 \%$ Tween 20 and then washed once with $200 \mu 1$ of incubation buffer $(0.05 \%$ (w/v) BSA in PBS- $-0.05 \%$ Tween 20). Wells were then incubated for $3 \mathrm{hrs}$ at $25^{\circ} \mathrm{C}$ with $50 \mu \mathrm{l}$ of ChiA-FL, ChiA-NT, ChiA-N1, ChiAN2, ChiA-N3, ChiA-CTD, ChiA-CTD ${ }^{\text {5504A }}$, ChiA-CTD ${ }^{\mathrm{H} 506 \mathrm{~A}}, \mathrm{ChiA}^{-C_{T} D^{\mathrm{E} 543 \mathrm{M}} \text {, ChiA-CTD }}{ }^{\mathrm{H} 544 \mathrm{~A}}$, ChiA$\mathrm{CTD}^{\mathrm{N} 547 \mathrm{~A}}$ and ChiA-CTD ${ }^{\mathrm{Q} 55 \mathrm{~A}}$ at $10 \mu \mathrm{M}$ in incubation buffer. This was followed by four washes with $200 \mu \mathrm{l}$ of incubation buffer and incubation with $50 \mu \mathrm{l}$ of anti-His-HRP antibody (Sigma), diluted 1:2000 in incubation buffer for $1 \mathrm{hr}$ at $24^{\circ} \mathrm{C}$. After four washes with $200 \mu \mathrm{l}$ of incubation buffer, $150 \mu \mathrm{l}$ of $o$ Phenylenediamine dihydrochloride (Sigma) was added for $30 \mathrm{~min}$ and then data was recorded at 450 $\mathrm{nm}$.

Assay for mucin binding to bacteria - L. pneumophila wild-type strain 130b and chiA mutant NU319, both harbouring a GFP-expressing plasmid $(69,73)$, were incubated for 3 days on BCYE agar containing IPTG at $1 \mathrm{mM}$. Bacteria were suspended in PBS to an OD of 0.3 (i.e., 1 x $10^{9} \mathrm{CFU}$ per ml), and then $1 \mathrm{ml}$ of the suspension was statically incubated with either $100 \mu \mathrm{g}$ of type II porcine stomach mucins or type III porcine stomach mucins or PBS alone for $1 \mathrm{~h}$ at $25^{\circ} \mathrm{C}$ or $37^{\circ} \mathrm{C}$. Following three washes each consisting of a 1-ml PBS wash solution and a 5-min centrifugation step at $4000 \mathrm{x} g$ (for the $37^{\circ} \mathrm{C}$ samples) or $8000 \mathrm{x} g$ (for the $25^{\circ} \mathrm{C}$ samples), bacteria were incubated with $7.5 \mu \mathrm{g}$ of Texas Red-tagged wheat germ agglutinin (WGA) for $15 \mathrm{~min}$ at $25^{\circ} \mathrm{C}$ in order to detect mucins bound to the bacteria. After three further washes, as indicated above, the bacteria were resuspended in $1 \mathrm{ml}$ PBS and finally analysed on a BD LSRII flow cytometer using a Texas Red filter and GFP Filter (75).

Immunoblot for detecting secreted mucinase activity - L. pneumophila strains that had been grown for three days on BCYE agar were suspended into $20 \mathrm{ml}$ of BYE broth to an $\mathrm{OD}_{660}$ of 0.3 and grown overnight at $37^{\circ} \mathrm{C}$ to an $\mathrm{OD}_{660}$ of $3.0-3.3$. Bacteria were sub-cultured into fresh BYE medium to an $\mathrm{OD}_{660}=0.3$ and grown, with shaking, to an $\mathrm{OD}_{660}$ of 1.0, which corresponded to the mid-log phase. Supernatants were collected, filtered through a $0.22-\mu \mathrm{m}$ filter, and concentrated using $10-\mathrm{kDa}$ Amicon concentrators (EMD Millipore UFC901024). $200 \mu 1$ of concentrated supernatants were incubated with 200 or $400 \mu \mathrm{g}$ of type II porcine stomach mucins. As controls, the mucins were either incubated in uninoculated BYE broth or in BYE broth containing $50 \mu 1$ of a known mucinase cocktail, which 
consisted of $10 \mu \mathrm{l}$ each of pepsin $(0.5 \mathrm{mg} / \mathrm{ml})$, pronase $(10 \mathrm{mg} / \mathrm{ml}), \mathrm{B}-\mathrm{N}$-acyltylglucosamidase $(2.5 \mathrm{M})$, fucosidase $(5 \mathrm{U} / \mathrm{ml})$, and DTT (1M) dissolved in $940 \mu \mathrm{lof} \mathrm{ddH}_{2} 0$. The various samples were incubated statically for $3 \mathrm{~h}$ at $25^{\circ} \mathrm{C}$ and then subjected to electrophoresis prior to immunoblotting (76). Specifically, reactions were stopped by adding $200 \mu \mathrm{l}$ of $2 \mathrm{x}$ Laemmli buffer and incubating for 5 min at $100^{\circ} \mathrm{C}$, and $35 \mu 1$ of each sample was electrophoresed through a Criterion 4-20\% SDS-PAGE gel (Biorad 5671094) for $1.5 \mathrm{~h}$ at 250 volts, i.e., until the 55-kDa MW marker migrated to the bottom of the gel. The separated reaction products were transferred onto PVDF membrane over the course of 13 min using the semi-dry Invitrogen Power-Blotter and Power Blotter transfer blotting solution. Following incubation in 1\% BSA in TBST for $1 \mathrm{~h}$ at room temperature, the membranes were incubated overnight at $4^{\circ} \mathrm{C}$ with biotinylated wheat germ agglutinin that had been diluted 1:2000 (from a $1 \mathrm{mg} / \mathrm{ml}$ stock) in TBST with BSA. After three, 5-min washes with TBST buffer, the membranes were further incubated for $1 \mathrm{~h}$ at $37^{\circ} \mathrm{C}$ with Aviden-HRP that had been diluted 1:2000 in BSA-containing TBST. Finally, subsequent to a series of washes, the blot was incubated for 1 min in $2 \mathrm{ml}$ Amersham ECL reagent and then exposed to X-ray film.

Immunoblot for detecting recombinant ChiA mucinase activity - Partially purified type II porcine stomach mucins (Sigma) at $0.04 \%(\mathrm{w} / \mathrm{v})$ in PBS were incubated for $24 \mathrm{hrs}$ at $25^{\circ} \mathrm{C}$ with $10 \mu \mathrm{M} \mathrm{ChiA-}$ FL (with and without $5 \mathrm{mM}$ EDTA), E. coli Ssle (with and without $5 \mathrm{mM}$ EDTA) or PBS as a negative control. These were then run on a $1 \%(\mathrm{w} / \mathrm{v})$ agarose, $0.1 \%(\mathrm{w} / \mathrm{v})$ SDS gel at $23 \mathrm{~V}$ in TAE buffer containing $0.1 \%(\mathrm{w} / \mathrm{v})$ SDS for $14 \mathrm{hrs}$ and then transferred onto a PVDF membrane by blotting. The membrane was blocked for $1 \mathrm{hr}$ with $0.1 \%(\mathrm{w} / \mathrm{v})$ bovine serum albumin (BSA) in PBS- $0.05 \%$ Tween 20 at $25^{\circ} \mathrm{C}$, followed by the addition of $1 \mu \mathrm{g} / \mathrm{ml}$ biotinylated wheatgerm lectin agglutinin for $2 \mathrm{hrs}$ at $25^{\circ} \mathrm{C}$. This was then incubated with avidin-HRP $\left(1: 2000\right.$ dilution) for $1 \mathrm{hr}$ at $25^{\circ} \mathrm{C}$ and then treated with enhanced chemiluminescence substrate (ECL; Pierce) before detection by enhanced chemiluminescence.

Detection of recombinant ChiA mucinase activity by NMR - Type II porcine stomach mucins (Sigma) at $0.5 \%(\mathrm{w} / \mathrm{v})$ in PBS- $10 \% \mathrm{D}_{2} \mathrm{O}$ were incubated for $12 \mathrm{hrs}$ at $25^{\circ} \mathrm{C}$ with $10 \mu \mathrm{M}$ ChiA-FL (with and without 5 mM EDTA), ChiA-NT, ChiA-CTD (with and without 5 mM EDTA), ChiA-CTD ${ }^{\mathrm{E} 543 \mathrm{M}}$, ChiA$\mathrm{CTD}^{\text {D504A }}$, ChiA-CTD ${ }^{\mathrm{H} 506 \mathrm{~A}}$, ChiA-CTD ${ }^{\mathrm{H} 544 \mathrm{~A}}$, ChiA-CTD ${ }^{\mathrm{N} 547 \mathrm{~A}}$, ChiA-CTD ${ }^{\mathrm{Q} 595 \mathrm{~A}}$, E. coli SslE (with and without $5 \mathrm{mM}$ EDTA) or PBS a negative control. Samples were then analysed by NMR at $25^{\circ} \mathrm{C}$ using a Bruker Avance III $700 \mathrm{MHz}$ spectrometer equipped with cryoprobe.

Molecular Dynamics - MD simulations and analyses were performed using GROMACS 2016 v3 (77) using a protocol similar to Ref (78). The protein was described using the Amber99SB*-ILDN force field (79) and solvated using a truncated octahedral box of TIP3P water molecules. A minimal distance of $12 \AA$ was set between the protein and the walls of the box. The charge of the ionisable residues was 
set to that of their standard protonation state at $\mathrm{pH} 7 . \mathrm{Zn}^{2+}$ ions were added by randomly replacing water molecules. A high $\mathrm{Zn}^{2+}$ concentration $(0.75 \mathrm{M})$ was used to have a faster sampling of possible $\mathrm{Zn}^{2+}$ sites around the protein surface. $\mathrm{Cl}^{-}$counterions were added to neutralise the system.

Periodic boundary conditions were applied. The equations of motion were integrated using the leapfrog method with a 2-fs time step. The LINCS (80) algorithm was chosen to constrain all covalent bonds in the protein, while SETTLE (81) was used for water molecules. The Particle Mesh Ewald (PME) (82) method was used for electrostatic interactions, with a 9- $\AA$ cutoff for the direct space sums, a 1.2- $\AA$ FFT grid spacing, and a 4-order interpolation polynomial for the reciprocal space sums. A 9- $\AA$ cutoff was used for van der Waals interactions. Long-range corrections to the dispersion energy were included.

Each system was minimised through 3 stages with 2000 (positional restraints on heavy atoms) +3000 steps of steepest descent, followed by 2000 steps of conjugate gradient. Positional restraints on heavy atoms were initially set to $4.8 \mathrm{kcal} / \mathrm{mol} / \AA^{2}$ and they were gradually decreased to 0 in $1.5 \mathrm{~ns}$, while the temperature was increased from 200 to $300 \mathrm{~K}$ at constant volume. The system was then allowed to move freely and was subjected to 1 -ns equilibration in NVT conditions at $\mathrm{T}=300 \mathrm{~K}$. This was followed by a 2-ns equilibration in NPT conditions with $\mathrm{T}=300 \mathrm{~K}$ and $\mathrm{p}=1$ bar. For these equilibration steps, the Berendsen (83) algorithm was used for both temperature and pressure regulation with coupling constants of 0.2 and $1 \mathrm{ps}$, respectively. At last, a 2-ns NPT equilibration was run after switching to the v-rescale thermostat (84) with a coupling constant of 0.1 ps and the Parrinello-Rahman barostat (85) with a coupling constant of 2 ps. Production NPT runs were then performed for $50 \mathrm{~ns}$, saving the coordinates every 1 ps. Multiple replicas (34) were run, with each replica starting from a different configuration of the ions around the protein, for an aggregated simulation time of $1.7 \mu \mathrm{s}$ (34 X $50 \mathrm{~ns}$ ). The spatial distribution function (86) (sdf) of $\mathrm{Zn}^{2+}$ around the protein was calculated with the $g m x$ spatial tool from GROMACS. Trajectories from the different replicas were first concatenated together and each frame was aligned through a best-fit superposition to the starting frame using the protein coordinates. A 0.5 - $\AA$ grid spacing was used for the sdf calculation. The average of non-null sdf values was calculated and isosurfaces connecting points with $\mathrm{sdf}=20,25$ and $30 \mathrm{x}$ average sdf were considered.

\section{References}

45. Hsieh YC, et al. (2010) Crystal structures of Bacillus cereus NCTU2 chitinase complexes with chitooligomers reveal novel substrate binding for catalysis: a chitinase without chitin binding and insertion domains. $J$ Biol Chem 285(41):31603-31615.

46. Yaniv O, et al. (2014) Fine-structural variance of family 3 carbohydrate-binding modules as extracellular biomass-sensing components of Clostridium thermocellum anti-sigmaI factors. Acta Crystallogr D Biol Crystallogr 70(Pt 2):522-534.

47. Yaniv O, et al. (2012) Structure of CBM3b of the major cellulosomal scaffoldin subunit ScaA from Acetivibrio cellulolyticus. Acta Crystallogr Sect F Struct Biol Cryst Commun 68(Pt 1):8-13. 
48. Shimon LJ, et al. (2000) Structure of a family IIIa scaffoldin CBD from the cellulosome of Clostridium cellulolyticum at 2.2 A resolution. Acta Crystallogr D Biol Crystallogr 56(Pt 12):1560-1568.

49. Xu GY, et al. (1995) Solution structure of a cellulose-binding domain from Cellulomonas fimi by nuclear magnetic resonance spectroscopy. Biochemistry 34(21):6993-7009.

50. McDonough MA, Kadirvelraj R, Harris P, Poulsen JC, \& Larsen S (2004) Rhamnogalacturonan lyase reveals a unique three-domain modular structure for polysaccharide lyase family 4. FEBS Lett 565(1-3):188-194.

51. Brunecky R, et al. (2012) Structure and function of the Clostridium thermocellum cellobiohydrolase A X1-module repeat: enhancement through stabilization of the CbhA complex. Acta Crystallogr D Biol Crystallogr 68(Pt 3):292-299.

52. Bisig D, Weber P, Vaughan L, Winterhalter KH, \& Piontek K (1999) Purification, crystallization and preliminary crystallographic studies of a two fibronectin type-III domain segment from chicken tenascin encompassing the heparin- and contactin-binding regions. Acta Crystallogr D Biol Crystallogr 55(Pt 5):1069-1073.

53. Davis IW, Murray LW, Richardson JS, \& Richardson DC (2004) MOLPROBITY: structure validation and all-atom contact analysis for nucleic acids and their complexes. Nucleic Acids Res 32(Web Server issue):W615-619.

54. Kabsch W (2010) Xds. Acta Crystallogr D Biol Crystallogr 66(Pt 2):125-132.

55. Evans P (2006) Scaling and assessment of data quality. Acta Crystallogr D Biol Crystallogr 62(Pt 1):72-82.

56. Winter $\mathrm{G}$ (2010) xia2: an expert system for macromolecular crystallography data reduction. Journal of Applied Crystallography 43(1):186-190.

57. Schneider TR \& Sheldrick GM (2002) Substructure solution with SHELXD. Acta Crystallogr D Biol Crystallogr 58(Pt 10 Pt 2):1772-1779.

58. Vonrhein C, Blanc E, Roversi P, \& Bricogne G (2007) Automated structure solution with autoSHARP. Methods Mol Biol 364:215-230.

59. Lamzin VS \& Wilson KS (1993) Automated refinement of protein models. Acta Crystallogr D Biol Crystallogr 49(Pt 1):129-147.

60. Emsley P \& Cowtan K (2004) Coot: model-building tools for molecular graphics. Acta Crystallogr D Biol Crystallogr 60(Pt 12 Pt 1):2126-2132.

61. Murshudov GN, Vagin AA, \& Dodson EJ (1997) Refinement of macromolecular structures by the maximum-likelihood method. Acta Crystallogr D Biol Crystallogr 53(Pt 3):240-255.

62. Painter J \& Merritt EA (2005) A molecular viewer for the analysis of TLS rigid-body motion in macromolecules. Acta Crystallogr D Biol Crystallogr 61(Pt 4):465-471.

63. Painter J \& Merritt EA (2006) Optimal description of a protein structure in terms of multiple groups undergoing TLS motion. Acta Crystallogr D Biol Crystallogr 62(Pt 4):439-450.

64. Konarev PV, Volkov VV, Sokolova AV, Koch MHJ, \& Svergun DI (2003) PRIMUS: a Windows PC-based system for small-angle scattering data analysis. Journal of Applied Crystallography 36(5):1277-1282.

65. Svergun D (1992) Determination of the regularization parameter in indirect-transform methods using perceptual criteria. Journal of Applied Crystallography 25(4):495-503.

66. Bernado P, Mylonas E, Petoukhov MV, Blackledge M, \& Svergun DI (2007) Structural characterization of flexible proteins using small-angle X-ray scattering. $J$ Am Chem Soc 129(17):5656-5664.

67. Tria G, Mertens HD, Kachala M, \& Svergun DI (2015) Advanced ensemble modelling of flexible macromolecules using X-ray solution scattering. IUCrJ 2(Pt 2):207-217.

68. Elder BL, Boraker DK, \& Fives-Taylor PM (1982) Whole-bacterial cell enzyme-linked immunosorbent assay for Streptococcus sanguis fimbrial antigens. J Clin Microbiol 16(1):141-144.

69. DebRoy S, Dao J, Soderberg M, Rossier O, \& Cianciotto NP (2006) Legionella pneumophila type II secretome reveals unique exoproteins and a chitinase that promotes bacterial persistence in the lung. Proc Natl Acad Sci U S A 103(50):19146-19151.

70. Cianciotto NP \& Fields BS (1992) Legionella pneumophila mip gene potentiates intracellular infection of protozoa and human macrophages. Proc Natl Acad Sci U S A 89(11):5188-5191. 
71. Moffat JF, Edelstein PH, Regula DP, Jr., Cirillo JD, \& Tompkins LS (1994) Effects of an isogenic Zn-metalloprotease-deficient mutant of Legionella pneumophila in a guinea-pig pneumonia model. Mol Microbiol 12(5):693-705.

72. Cianciotto NP, Bangsborg JM, Eisenstein BI, \& Engleberg NC (1990) Identification of miplike genes in the genus Legionella. Infect Immun 58(9):2912-2918.

73. Truchan HK, Christman HD, White RC, Rutledge NS, \& Cianciotto NP (2017) Type II Secretion Substrates of Legionella pneumophila Translocate Out of the Pathogen-Occupied Vacuole via a Semipermeable Membrane. MBio 8(3).

74. Chatfield CH, Mulhern BJ, Burnside DM, \& Cianciotto NP (2011) Legionella pneumophila $\mathrm{LbtU}$ acts as a novel, TonB-independent receptor for the legiobactin siderophore. $J$ Bacteriol 193(7):1563-1575.

75. Model MA, Reese JL, \& Fraizer GC (2009) Measurement of wheat germ agglutinin binding with a fluorescence microscope. Cytometry A 75(10):874-881.

76. Issa SM, Schulz BL, Packer NH, \& Karlsson NG (2011) Analysis of mucosal mucins separated by SDS-urea agarose polyacrylamide composite gel electrophoresis. Electrophoresis 32(24):3554-3563.

77. Abraham MJ, et al. (2015) GROMACS: High performance molecular simulations through multi-level parallelism from laptops to supercomputers. SoftwareX 1-2:19-25.

78. Hashem S, Tiberti M, \& Fornili A (2017) Allosteric modulation of cardiac myosin dynamics by omecamtiv mecarbil. PLoS Computational Biology 13(11):e1005826-1005826.

79. Lindorff-Larsen K, et al. (2012) Systematic validation of protein force fields against experimental data. PLoS ONE 7(2):e32131.

80. Hess B, Bekker H, \& Berendsen HJC (1997) LINCS: a linear constraint solver for molecular simulations. Journal of computational chemistry 18(12):1463-1472.

81. Miyamoto S \& A. KP (1992) Settle: An analytical version of the SHAKE and RATTLE algorithm for rigid water models. Journal of computational chemistry 13(8):952--962.

82. Essmann U, et al. (1998) A smooth particle mesh Ewald method. The Journal of Chemical Physics 103(19):8577--8593.

83. Berendsen HJC, Postma JPM, Gunsteren WF, Di Nola A, \& Haak JR (1984) Molecular dynamics with coupling to an external bath. The Journal of Chemical Physics 81(9):3684-3690 .

84. Bussi G, Donadio D, \& Parrinello M (2007) Canonical sampling through velocity rescaling. $J$ Chem Phys 126(1):014101.

85. Parrinello M \& Rahman A (1981) Polymorphic transitions in single crystals: A new molecular dynamics method. Journal of Applied Physics 52(9):7182-7190.

86. Fornili A, Autore F, Chakroun N, Martinez P, \& Fraternali F (2012) Protein-water interactions in MD simulations: POPS/POPSCOMP solvent accessibility analysis, solvation forces and hydration sites. Methods in molecular biology 819(Chapter 23):375-392. 